\title{
Properties Exploring and Information Mining in Consumer Community Network: A Case of Huawei Pollen Club
}

\author{
Qingchun Meng $\mathbb{D}^{1,2}$ Zhen Zhang $\mathbb{D}^{1,2,3}$ Xiaole Wan $\mathbb{D}^{2,4}$ and Xiaoxia Rong $\mathbb{D}^{2,3}$ \\ ${ }^{1}$ School of Management, Shandong University, Jinan 250100, China \\ ${ }^{2}$ Research Center for Value Co-Creation Network, Shandong University, Jinan 250100, China \\ ${ }^{3}$ School of Mathematics, Shandong University, Jinan 250100, China \\ ${ }^{4}$ School of Management, Ocean University of China, Qingdao 266100, China
}

Correspondence should be addressed to Xiaoxia Rong; rongxiaoxia@sdu.edu.cn

Received 12 July 2018; Accepted 10 October 2018; Published 6 November 2018

Academic Editor: Yongtang Shi

Copyright (C) 2018 Qingchun Meng et al. This is an open access article distributed under the Creative Commons Attribution License, which permits unrestricted use, distribution, and reproduction in any medium, provided the original work is properly cited.

\begin{abstract}
Substantial changes took place in the role of consumers in the supply chain with the development of practices. They became creators from consumers of product values. More and more consumers express their consumption experiences by posting in network community. Consumer community network is an important place for feedback of product experiences and facilitating product innovation in future. Manufacturers can promote improvement and innovation of products by exploring effective information on the consumer community network, thus improving the experience level of consumers. Therefore, how to explore information in topics (posts) and their relationships becomes very important. Is it possible to describe the structure of consumer community network by complex network and explore information about products and consumers? There is important and positive significance to study the collaborative innovation in the supply chain in which consumers participate. In this paper, the consumer community network was constructed by Boolean retrieve programming and discussed in the methodology and empirical way based on the community data of Huawei P10/P10 Plus. In methodology, interaction difference and uniformity within consumer community were explored by the density of isolated nodes and generalized variance of degree of network. In empirical studies, community network users were divided into ordinary user group, intermediary user group, and enterprise user group according to empirical data, and corresponding interaction networks were constructed. A contrastive analysis on the interaction of these three groups was carried out by combining the existing properties and innovative properties. Topics in each network were put in the order according to significance. Research conclusions have important significance to enrich the network analysis methods, explore the effective information in consumer community network, facilitate product improvement and innovations, and improve the experience level of consumers.
\end{abstract}

\section{Introduction}

The social, biological, physical, and technological networks often contain some interactive individuals, which make the complex network, the extension of graph theory, an edged tool to analyze internal structure and dynamic involutions of these networks [1-3]. For example, Boolean network is the combination of the Boolean operation with network structure to solve difficult problems in biological area [4-6]. However, interaction of individuals in the research system of social network services (SNS) [7] has become an important component for rapid high-efficiency propagation of information and discovery of key nodes in the studying networks [8]. The academic circles often abstract the corresponding "nodes" and "edges" from the network data $[9,10]$ and then construct the network model to analyze its topological properties, including average degree [11], density of graph [12], diameter of graph [13], eigenvector centrality [14], average clustering coefficient [15], etc. This network model not only is conducive to explore deep-layer information like key information propagation $[16,17]$ and community structure $[18,19]$ but also helps enterprises in consumer service management $[20,21]$.

Nevertheless, with the rapid network development, the "Internet + " technologies that combine information technologies arouse the significant impacts of consumers on the market $[22,23]$. More and more consumers are active 
in expressing their experiences of some bought products or giving purchase suggestions to others $[24,25]$ in the consumer community formed by different media, including cell phone, PC, or PAD [26]. Manufacturers explore these opinions or suggestions deeply for the purpose of product updating or improvement [27]. Consequently, the role of consumers in the supply chain is changed substantially. They shifted from the consumer of product values into creators [28]. In structure, these consumer communities are more like the derived structures of social network [29]. Therefore, network community has become the important way for communication between enterprises and consumers and information mining [30]. Hence, enterprises shall understand the immediate opinions of consumers in the consumer community, which is very important to develop potential products.

Among consumer electronics, cell phone has become the mobile computer in people's daily life and it is related to various living aspects of users [31]. Moreover, the lifecycle of cell phone is going to be shortened to less than 2 years, which is attributed to the high replacement rate and frequent use [32]. With the progress in informationalization, the brand community and consumer community are developed accordingly. Consumer experience and other information in these consumer communities facilitate the continuous improvement of cell phone in view of some perspective [33]. Currently, Huawei is the leader in the Chinese smartphone market, followed by Xiaomi and OPPO. The market shares of these brands in the fourth quarter in 2017 reached 10.2\%, $7.2 \%$, and $6.9 \%$, respectively [34]. They all established their own official consumer communities to exhibit their product design philosophies and accept suggestions from consumers. For example, by May 2018, the number of the published posts on the Huawei Pollen Club about P10/P10 Plus reached $1,556,433$ [35], the number of published posts on Huawei P20 reached 261,691 [36], and the number of published posts on Huawei Mate10 reached 1,293,712 [37]. These posts covered tremendous product information and experiences of consumers [38].

Considering the extreme importance of consumers to manufacturers, what is the structure of consumers in the web community? What cell phone topics are different users concerned with in the community? Which connections are there between different topics and how strong such connection is? What characteristics are there in the changes of topics as time goes on?

On this basis, this paper is going to explore data from the Huawei P10/P10 Plus community to address above problems mainly from methodologies and empirical studies. In methodology, interaction difference and uniformity among different consumer community networks as well as key time points of the network dynamics were explored by the density of isolated nodes, generalized variance of degree of network and node sequential emergence determination coefficient. In empirical studies, community network users were divided into Ordinary User Group (OUG), Intermediary User Group (IUG), and Enterprise User Group (EUG) according to empirical data, and corresponding interaction networks were constructed. A contrastive analysis on the interaction of these three groups was carried out by combining the existing properties and innovative properties. Topics in each network were put in the order according to significance. Secondly, the emergence law of cell phone topic lifecycle was analyzed by combining the theory of product lifecycle with node sequential emergence determination coefficient.

The remainder of this paper is organized as follows. Section 2 is literature review on existing research methods. Section 3 extracts topics and classifies users according to posting data of Huawei P10/P10 Plus users. Section 4 constructs the complex network models for three types of users, respectively. Some new properties, such as density of isolated nodes, generalized variance of degree of network, and node sequential emergence determination coefficient, are proposed. A statistical analysis is carried out by combining these new properties with the traditional statistical properties. Section 5 further analyzes "leaders" in networks and explores information like closeness and significance of topics. Section 6 elaborates enlightenments to enterprise management which are gained from empirical analysis. Finally, the corresponding sketch of methods is displayed in Figure 1.

\section{Literature Review}

There are rather more literature reports about the consumer interaction from 4 ways to explore the law behind it, which are stated below.

2.1. Consumer Interaction. Many studies on consumer interaction have been reported worldwide. Georgi and Mink (2013) explored the positive impacts of interaction of electronic (online) consumers on performance of innovative enterprises [39]. Smaliukiene et al. (2015) analyzed consumers' discussions of network construction in the online forum provided by suppliers when they studied the online tourism service, finding that consumer interaction was conducive to analyze procedures in global online tourism service departments effectively [40]. Bruhn $\mathrm{M}$ et al. (2014) performed the online investigation of three virtual B2B brand communities and verified the positive effect of consumer interaction on brand loyalty by an empirical study [41]. Millán et al. (2016) analyzed the impacts of consumer interaction on satisfaction to vocation by the fuzzy qualitative method, finding that quality, strength, value, and influence of consumer interaction are important conditions of vocation experience [42]. Based on 821 samples, Wei et al. (2017) discussed the fundamental mechanism of influences of consumer interaction on experiences of participants. They reported that specialized knowledge communication and social emotional support during the consumer interaction are vital to the implementation of activities of service providers [43]. Chen et al. (2011) discussed the influence of customer interaction on the relationship quality between service companies and customers by constructing a conceptual model and found that such relationship quality can be improved by improving the consumer interaction methods [44]. However, it is easy to know that all above studies are mainly macroscopic analyses on consumers' behavior based on survey questionnaire but neglect the difference among different consumer community 


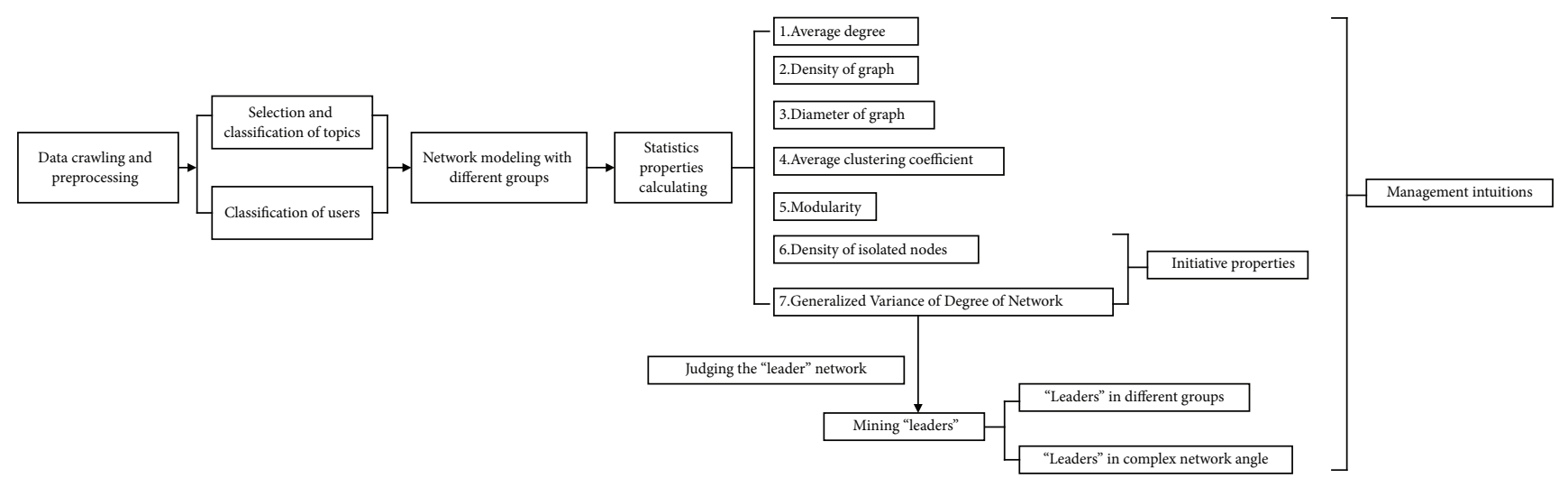

FIgURE 1: Sketch of the exploration study.

networks. Few scholars have discussed differences of interaction contents in the community brought by changes of product lifecycles.

\subsection{Research Methods of Consumer Online Community. From} the view of methodology, there are mainly four methods in research of customer interactive behavior containing statistical methods, structure equation modelling, experiment and case study and complex network analysis, which are stated as below.

In method of statics, Oh., et al. (2015), classified the test subjects of 315 university students as three groups and conducted two-way ANOVA to test the hypotheses of the research model [45]. Zollet and Back (2015) collected data from 138 firms in Switzerland and Germany and analyzed with multiple regression analysis [46]. Khan et al. (2016) analyzed 1,922 brand posts from five different brands of a single product category in three different countries and used ordinary least square and hierarchical moderation regression to test the hypotheses [47]. Nourikhah and Akbari (2016) used Bayesian data analysis with a generalized linear model (GLM) to estimate the overall satisfaction of the users in the form of the posterior distribution of opinions [48]. Wan et al. (2016) introduced least squares support vector machine (LSSVM) innovatively into the study on consumer electronics supply chains [23]. These studies took consumers as a whole, then from the perspective of the supply chain or enterprises, analyzing consumers' interaction impact on supply chain or their features. However, consumer network is not a simple whole, but a complex structure, which meets the structure of the general complex network and has its own characteristics at the same time.

Many scholars introduce structure equation modelling method to study consumer behavior in online community. Shobeiri et al. (2014) used structural equation modelling based on EQS 6.1 to assess the measurement and structural models [49]. Liou et al. (2015) adopted structural equation modeling to investigate the factors that influence users' use intentions regarding broadband television [50]. Islam and Rahman (2017) analyzed the data using structure equation modelling through a questionnaire survey of 430 Facebook users [51]. The structure equation modelling can explain features in customers interactive network; however it also ignores the structure of the customers communities which would leave out some detailed information like the important topics and customers.

In terms of experiment and case study method, Kilgour et al. (2015) employed depth interviews initially, followed by questionnaires, and then computer assisted content analysis was performed on 723 online media articles relating to social media marketing to identify semantic and conceptual relationships [52]. McKechnie and Nath (2016) explored this issue in an online experiment with 273 subjects browsing 4 websites offering identical products but with variable levels of interactivity and personalization features [53]. Chu et al. (2017) conducted two experiments to identify an effective communication strategy to facilitate social media marketing using a combination of communication facets such as frequency, direction, formality, and content [54]. Firstly, in these papers, experiment and case studies were conducted within a confined condition, which means that the participants are easy to be interrupted by some other reasons. Secondly, participants and case study could not represent the whole interactive network to some extent.

In complex network analysis method, Chiang and Wang (2015) extended research on the interactive features of product-review networks by considering the out degree centralization, density, and microstructure of product-review networks [55]. Li and $\mathrm{Gu}$ (2015) proposed an OSN link formation model from the perspective of user behavior, which reproduced degree distribution, clustering and degree correlation of OSN [56]. Andersen and Mørch (2016) classified user types through social network statistical analysis and constructed "user-topic" hybrid network with user interaction analysis of user posts [57]. Baumgartner and Peiper (2017) extended a novel method called stochastic block modeling to derive communities of cannabis consumers as part of a complex social network on Twitter [58]. Liu et al. (2017) proposed a complex network model with reviews as nodes by calculating reviews topics with latent Dirichlet allocation model and topic similarities among reviews with Pearson similarity [59]. These studies consider it from a complex network view, ignoring the statistics characteristics between the same type networks in different periods. 
TABLE 1: Classification of topics.

\begin{tabular}{|c|c|}
\hline Type & Topics \\
\hline System & $\begin{array}{c}\text { System, Upgrade, Lock screen, Unlock, Black screen, Font, Resolution, Update, Lightness, Color, Screen capture, Location, } \\
\text { Telephone, Net, Mode, Vague, Data, WIFI, Power off, Beta, Theme, Ring, Voice assistant, Heat, Wall paper, Desktop, NFC, } \\
\text { Root, 4G, Internet speed, GPS, Position }\end{array}$ \\
\hline Software & $\begin{array}{c}\text { WeChat, Fingerprint, Transposition card, Consumption, Message, Game, Flash back, Program, Code, Backups, Music, } \\
\text { Defrayment, Video, King Glory, Jingdong, Vmall, Weibo, QQ }\end{array}$ \\
\hline Hardware & $\begin{array}{l}\text { Life, Taking pictures, Power consumption, Charging, Memory, Pick-up hand, Camera, Light, Anti-fingerprint oleophobic } \\
\text { coating, Battery, Home key }\end{array}$ \\
\hline
\end{tabular}

In our paper, data were scrawled from club.huawei.com, which enable us to avoid interview effects [60] and some other possible negative influence accompanying survey research $[61,62]$. Later we will clean the data and build complex model.

\section{Data Crawling and Preprocessing}

3.1. Data Source. For topic type, Huawei community, Xiaomi community, and OPPO community emphasize on different topics. For example, the OPPO community focuses on camera performance of the phone. Huawei P10/P10 Plus community has relatively more topics, covering hardware, software, system, appearance design, and even price. More importantly, the community has stronger data integrity and accessibility. Although the Xiaomi community has many topics, it only displays the latest data, which were not as comprehensive as that of Huawei P10/P10 Plus community since February 2017. Hence, post data in the Huawei P10/P10 Plus community were collected in this paper for information mining by complex network.

In this paper, post data in the Huawei Pollen Club (HPC), a consumer community formed by Huawei P10/P10 Plus, from February $8^{\text {th }}, 2017$, to November $4^{\text {th }}, 2017$, were collected [35]. Members of the club participated in communication of relevant products after registration. In this club, consumers can raise questions and interact with others by replies, thus increasing understanding on Huawei products. On the other hand, Huawei can make responses in time, help them to solve ticklish questions, and explore problems that consumers are highly concerned according to consumers' information feedback in the community, thus enabling improvement of products during upgrading and increasing profits of the enterprise.

3.2. Initial Data Screening. A total of 125,163 data were collected initially, covering titles and contents of posts (excluding replies), user name, user level, and publishing time. Since user browsing or reply was updating dynamically and generated continuously during data acquisition, it was inevitable to generate some repeated data. In this paper, the latest state of the same post was applied. After selected operation, 78,320 data were retained. Later, 824 invalid data of banned to post, banned to login and shielded data because of advertisement and unrelated information were further eliminated. Finally, 77,496 valid data were kept.
3.3. Data Analysis and Processing. In this section, data were analyzed from extraction of hot topics and user classification, which prepares for the construction of weighted network model in Section 4.

3.3.1. Extraction of Topics. Firstly, the core topics are extracted from what the users consider. Most of the data presented by users on the website are in the form of posts. It is necessary to extract the topics from the post in order to learn the needs of the users.

Through calculating the frequency of the topic combined with the features of phone via programming with Boolean operation to judge whether the topics occur in the post or not, 100 topics are selected (see Appendix A). After sorting the higher frequency ones, they are divided into three parts including system, software, and hardware, according to their feature, showed in Table 1.

3.3.2. Classification of Users. In order to specify interaction and different topic focus within community, users of the HPC can be divided into three groups according to functions and roles [63-68], namely, OUG, IUG, and EUG. The OUG refers to users who bought Huawei products and registered in the HPC. The IUG refers to users who have received official training of Huawei and are willing to answer questions of other users. The EUG refers to the official enterprise employees, covering technicians, salesmen, and publicists. Level labels and meaning of each group are listed in Table 2.

A statistical calculation on posting frequencies of all users of each level showed in Table 2 was made (see Appendix B), getting proportions of posts of three user groups in Figure 2.

It can be seen from Figure 2 that $99 \%$ posts were published by ordinary users, indicating that OUG is the main force. However, it still cannot replace the key role of the rest two groups in the community. Hence, different models were constructed to the OUG, IUG, and EUG, respectively.

\section{Weighted Network Analysis}

In this part, this paper introduces complex network analysis method. The nodes denote 61 topics in Table 1 , and if a user mentions two topics $K_{i}$ and $K_{j}$, in a post title and text at the same time, it suggests that there is a close relationship between these two topics, which corresponds with an edge between nodes $i$ and $j$. This step is achieved by Boolean retrieve in programming. The weight of edges denotes the number of users. That forms undirected weighted network. 
TABLE 2: Meaning of HPC.

\begin{tabular}{|c|c|c|}
\hline $\begin{array}{l}\text { Group } \\
\text { name }\end{array}$ & Level name & Meaning of levels \\
\hline \multirow{13}{*}{ OUG } & Newcome & OUG level 1 \\
\hline & Beginners & OUG level 2 \\
\hline & Preliminary learners & OUG level 3 \\
\hline & Small success & OUG level 4 \\
\hline & Further progress & OUG level 5 \\
\hline & Master & OUG level 6 \\
\hline & The dedicated & OUG level 7 \\
\hline & The self-contained & OUG level 8 \\
\hline & Great success & OUG level 9 \\
\hline & Pinnacle & OUG level 10 \\
\hline & Magic master & OUG level 11 \\
\hline & The matchless & OUG level 12 \\
\hline & Limited member & Limited use due to long unregister or other reasons \\
\hline \multirow{14}{*}{ IUG } & Hot fans & Activating area atmosphere and eager to answer the questions of other users \\
\hline & Expert fans & $\begin{array}{c}\text { Willing to experience the latest products and ROM, positive feedback problems during use with } \\
\text { good language organization, having enough time to participate in product evaluation, and } \\
\text { enjoying taking pictures and reading experience }\end{array}$ \\
\hline & Female fans & Special female members dedicated to women's topics \\
\hline & Internal manager & On the basis of all Pollen member, an independent special user group with management authority \\
\hline & Internal expert & $\begin{array}{c}\text { Application for internal test, an independent special user group, with members of internal test } \\
\text { core group }\end{array}$ \\
\hline & Pollen director of city & $\begin{array}{c}\text { The core link of regional Pollen fans and participating in Huawei's deep marketing decision in the } \\
\text { region }\end{array}$ \\
\hline & $\begin{array}{l}\text { Pollen director of } \\
\text { universities }\end{array}$ & $\begin{array}{c}\text { The university club management of Huawei, assisting Huawei in the publicity and personnel } \\
\text { recruitment }\end{array}$ \\
\hline & Special forces of HPC & $\begin{array}{l}\text { A group of technical master trained by the Huawei for researching phone, sharing information } \\
\text { and solving problems for others }\end{array}$ \\
\hline & Moderator of HPC & $\begin{array}{l}\text { Management in various articles of the forum, and promoting the healthy development of the } \\
\text { forum }\end{array}$ \\
\hline & $\begin{array}{l}\text { Moderator of Huawei } \\
\text { Pollen Sub-club }\end{array}$ & Management in a group of forums \\
\hline & Moderator of game center & Management in game forums \\
\hline & HRT team & Providing experience of third party Rom version based on official Rom or other vendors \\
\hline & $\begin{array}{l}\text { Super-circle director of } \\
\text { HPC }\end{array}$ & $\begin{array}{l}\text { Maintaining circle order, activating circle discussion and discussion atmosphere, and establishing } \\
\text { good communication environment for Pollen members }\end{array}$ \\
\hline & Theme fans & $\begin{array}{c}\text { In order to get all the pollen to have a better experience, modifying the theme, making a custom } \\
\text { theme and so on }\end{array}$ \\
\hline \multirow{7}{*}{ EUG } & Pollen group & $\begin{array}{c}\text { Focusing on the Huawei mobile phone evaluation and guidance, solving common problems, } \\
\text { enhancing the interaction of pollen }\end{array}$ \\
\hline & Pollen group & $\begin{array}{c}\text { Focusing on the Huawei mobile phone evaluation and guidance, solving common problems, } \\
\text { enhancing the interaction of pollen }\end{array}$ \\
\hline & HPC team & The official management team of the club \\
\hline & Official team & Huawei official team \\
\hline & EMIUI product manager & Official product manager for the EMIUI system \\
\hline & EMIUI official team & The official team for developing the EMIUI system \\
\hline & Product manager & Huawei product manager \\
\hline
\end{tabular}



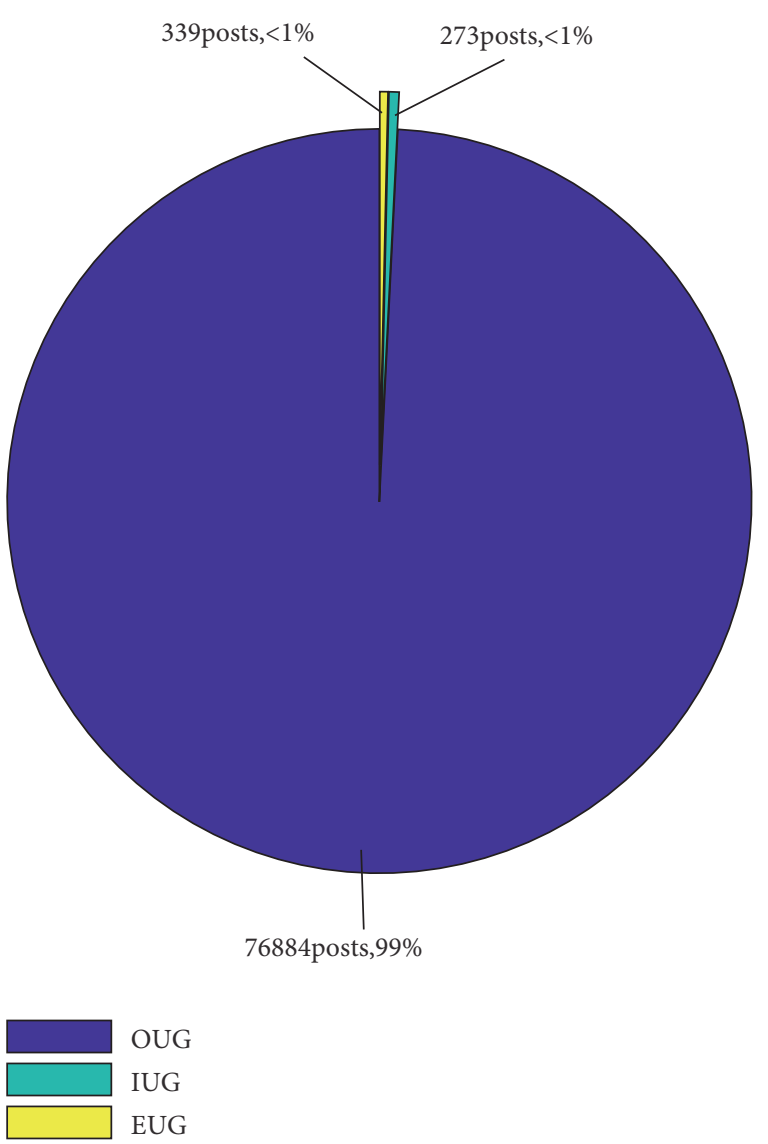

FIgURE 2: The ratio of posts of different groups.

Because different groups of users have different positions in the network, they play different roles. Therefore, this paper establishes networks according to users' groups.

4.1. Modeling of Networks. By using Gephi software, we get three groups of users' interaction networks, respectively, in Figures 3, 4, and 5. In the graphs, the nodes of the same color represent the same kind of community $[69,70]$. The size of the nodes represents the eigenvector centrality, that is, the power to control other topics. The color of the edge represents the number of people who focus on two topics at the same time. The deeper the color (purple) is, the more the people who are concerned about the two topics are, which shows that these two topics have strong correlation.

The interaction network of OUG is shown in Figure 3 Topics are divided into five communities: "Taking pictures," "System update and battery," "Fingerprint unlock," "APP," and "Internet speed," which reflects the system problems, software problems, and hardware problems users are concerning. However, the connection between "System" and "Update" has the deepest color among all topics" edges, indicating the high frequency of simultaneous mention of these two topics by users. This implies that the cell phone problems might be brought by system updating. In addition, "WeChat" is closely related to the "APP" community and topics of other communities, indicating that "WeChat" is the core application of OUG.

It is easy to note that edges in the network have relatively uniform color, which implies that users concern extensive problems. Besides, the OUG often proposes their questions by posting in the community and make partial or complete effective answers to problems of other users. They have strong uncertainty.

The interaction network of IUG is shown in Figure 4. The network is divided into two communities: "System applications" and "Hardware." Although problems still involve system, software, and hardware of cell phone, the system and applications are divided into one community, indicating that the IUG can classify topics effectively. Compared with the OUG, the IUG is aware of problems that the OUG has not noticed. For instance, "Pattern" is just a periphery topic in the interaction network of OUG, but it is a core topic in the interaction network of IUG and highly related to other topics.

Compared with the interaction network of OUG, edge color in the interaction network of IUG is not uniform. Many edges have deep color, especially in the "System applications" community. The IUG associates key topics that users are discussing effectively according to users' questions and offer corresponding answers. They fulfill the responsibility of answering questions authorized by the Huawei community.

In Figure 5, the interaction network of EUG is also divided into 3 communities: "System updating," "Taking pictures," and "Software applications." In the "Taking pictures" community, edges between any two topics have relatively deeper color, indicating that the Huawei officials pay attentions to propagation of the camera performance of cell phones. This is because Huawei officials regularly encourage OUG to exhibit their own pictures. Moreover, the topic "System" is strongly correlated with other topics.

Obviously, the IUG answers questions of users and summarizes topics. Based on the IUG, the Huawei officials answer questions related to "System," "Upgrade," and "Update." They also answered the "WeChat" problems that users are concerned. In other words, the EUG can not only guide the discussion themes in the community by observing the OUG and IUG but also answer problems of the OUG accurately.

By comparing these three networks, three characteristics are recognized:

(1) The number of hotspots of core topics increases gradually. The node size in networks represents the significance. Node size in the interaction network of OUG is more uniform than that in the interaction network of IUG, indicating that the OUG has more questions in both quantity and complexity. However, the IUG and EUG with experiences can explain topics specifically, thus increasing the number of core topics relatively. The concerned problems also present targeted variation.

(2) There are significant differences among different communities. The difference among different user groups is manifested by the number and members of communities. Just as definitions of IUG, it is mainly to classify problems of the OUG and give specific answers. Therefore, it only involves two communities. The EUG will cooperate with concerned points of the OUG and make corresponding 


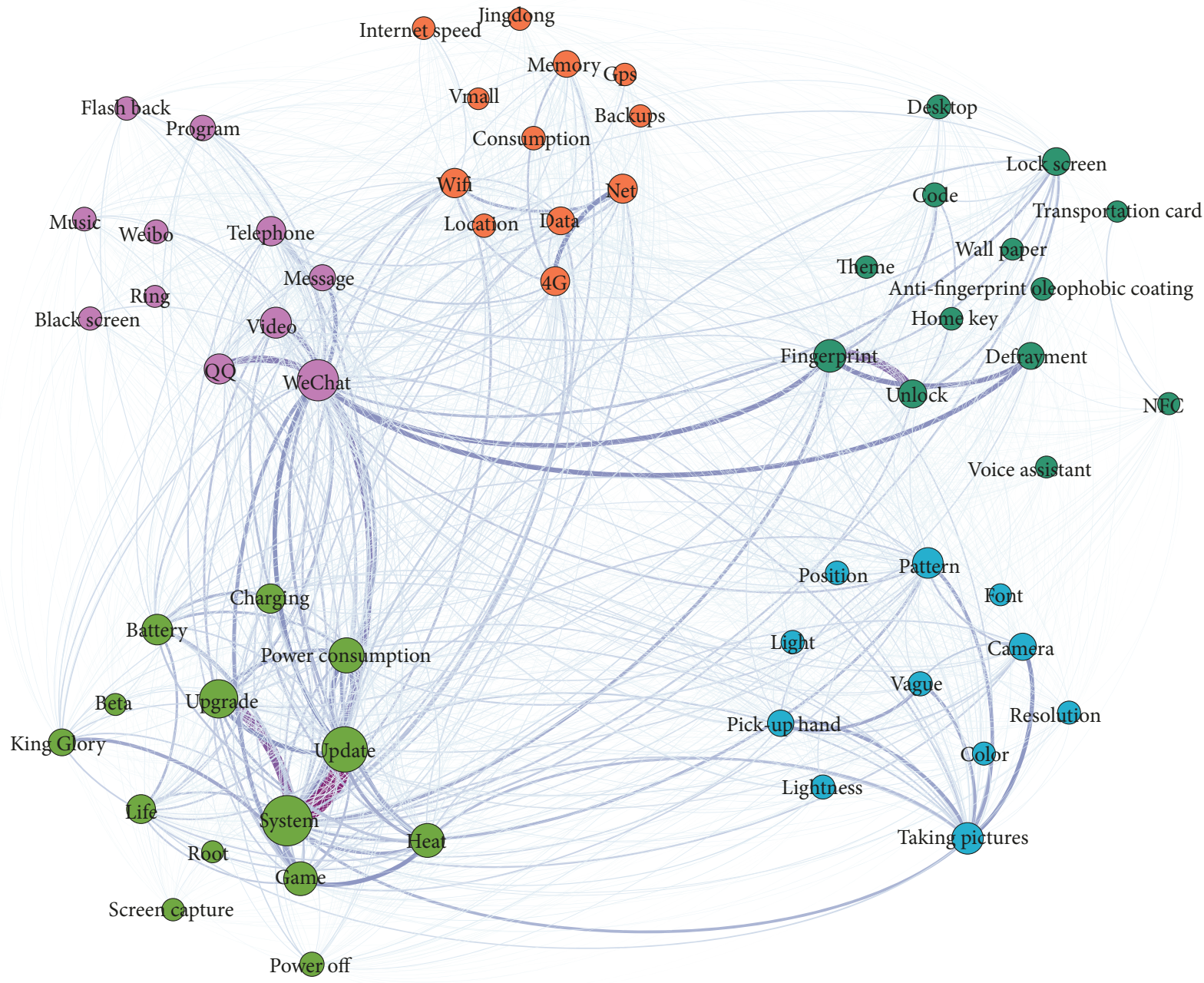

FIGURE 3: OUG interaction network.

guidance. Therefore, these two groups have similar number of communities. However, these two groups have certain differences in communities' members, which is caused by their different cognition degree on correlation degree of problems.

(3) The correlations of topics are significantly different. The OUG concerns all aspects of cell phone, because they have poor knowledge on roots of cell phone problems. Therefore, edges have relatively uniform color. In contrast, the IUG understands relevant problems of cell phone well. It highlights connections of different types of problems during reasonable standardizing of problems. The EUG is mainly to answer most questions of the OUG and propagate the system and unique camera performance of cell phone. Hence, only edges within these two communities are relatively deep.

4.2. Statistical Analysis of Networks. From the former descriptive analysis of three networks, the difference between them will be quantified by using complex network properties: let $\mathrm{G}(\mathrm{V}, \mathrm{E}, \mathrm{W})$ be a nonempty weighted graph with $|V|=n$ and $|E|=m \cdot A=\left(a_{i j}\right)_{n \times n}$ is the adjacency matrix of G, in which $a_{i j}$ is 1 if node $i$ and node $j$ are connected and 0 otherwise. Similarly, $A^{w}=\left(a_{i j}^{w}\right)_{n \times n}$, is the weighted adjacency matrix of G, in which $a_{i j}^{w}$ denotes the weight of the edge between node $i$ and node $j . W_{\text {all }}$ represents the sum of the weight of the edges in G. Through comparing the statistical properties between the constructed networks and relative null models, which includes average degree, density of graph, average clustering coefficient, diameter of graph, modularity, and initiative ones, containing density of isolated nodes, generalized variance of degree of network, we can specify the information value of networks, in which the null model denotes $G\left(V^{\prime}, E^{\prime}, W^{\prime}\right)$ with $\left|V^{\prime}\right|=|V|$ and $W_{\text {all }}=W_{\text {all }}^{\prime} \cdot W_{\text {all }}^{\prime}$ is the he sum of the weight of the edges of null model.

This paper use following statistical properties [69]: (1) Average degree: average degree, denoted $\langle k\rangle$, describes the mean of all nodes in the network. In this paper it represents the average of topics' relative topics. (2) Density of graph: density of graph, $\rho$, is the ratio of the existing number of the edges $m$ to its maximum possible number of edges. We use it to detect the density of topics network. (3) Diameter of graph: the diameter of graph, denoted by $d_{\text {max }}$, is defined 


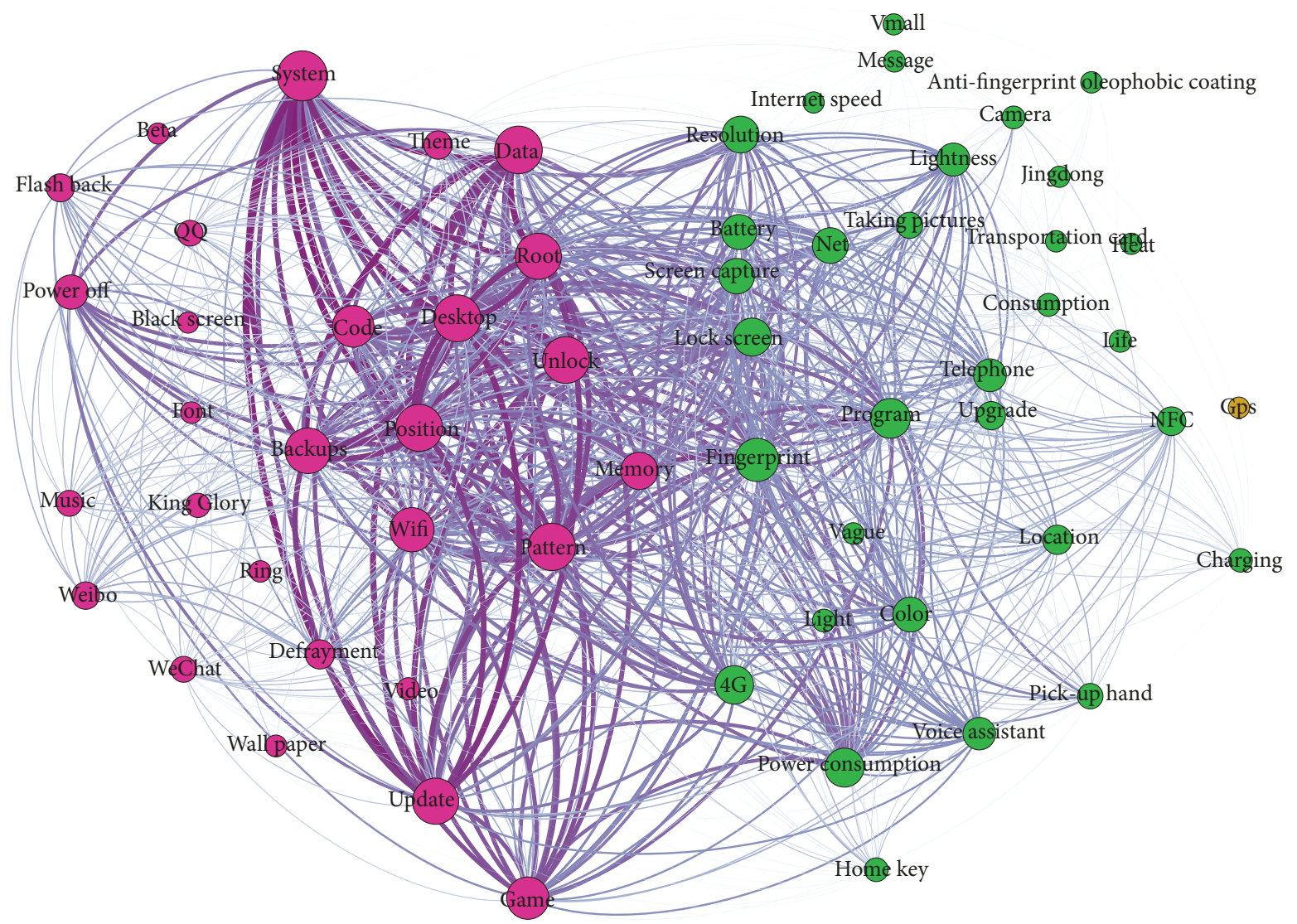

FIGURE 4: IUG interaction network.

to the largest of all distance in the graph. The smaller $d_{\max }$ is, the more stable network would be. This property can describe the closeness of the topics. (4) Average clustering coefficient: if there are edges between each two of nodes $i$, $j$, and $k$, then it forms a triangle. Thus, average clustering coefficient $\mathrm{C}$ is defined as the ratio of such triangles in graph G. It can describe the local stability of network. (5) Modularity is a measure of the level or degree to which a network's communities may be separated and recombined, which is a commonly used criterion for determining the quality of network partitions. It can classify the topics according to their associations. Although they can describe the general features of different networks, it is still necessary to measure the following features of networks.

The quantitative description of isolated topics and judgment rule of "leaders" network in weighted networks, which has nodes with special important status called "leaders" in it. The OUG network has no isolated topics; however, different circumstance occurs in the IUG and EUG, which means topics have different status among three groups. What is more, there are some researches on the judgment rule of "leader" network in unweighted networks but no one in weighted network like topics networks in this paper. Mining the "leaders" can guide EUG focus on important topics. If company can solve the timely, other problems would be modified.

Due to these demand for research, this paper proposes the following properties to dig out the properties of the networks.
4.2.1. Density of Isolated Nodes. Namely, isolated node $i$ satisfies

$$
\sum_{j=1}^{n} a_{i j}=0 \quad(i \in\{1,2, \ldots, n\})
$$

Therefore, density of isolated nodes $p_{a}$ is defined as the ratio of the number of isolated nodes $n_{a}$ to $n$. That is,

$$
p_{a}=\frac{n_{a}}{n}
$$

$p_{a}$ measures the connectivity of network, which means that the more connective network is, the smaller $p_{a}$ it would be. Traditional network analysis based on good connectivity of graph, lacks of this property. It can explore the difference due to interaction level between user groups; as a result some topics become isolated ones.

4.2.2. Generalized Variance of Degree of Network. Considering the nodes in undirected network, the generalized degree of each node is the sum of the weight of links between their neighbors. So the variance of all generalized degree in graph is the generalized variance of degree of network. It can judge whether G has "leaders" compared to the null model. We can use it to detect whether the network has "leaders" or not, as well as the uniformity of weight distribution. The thought of its definition comes from variance of degree of undirected unweighted graph [71]: if the degree of node $i$ denotes $d_{i}$, 


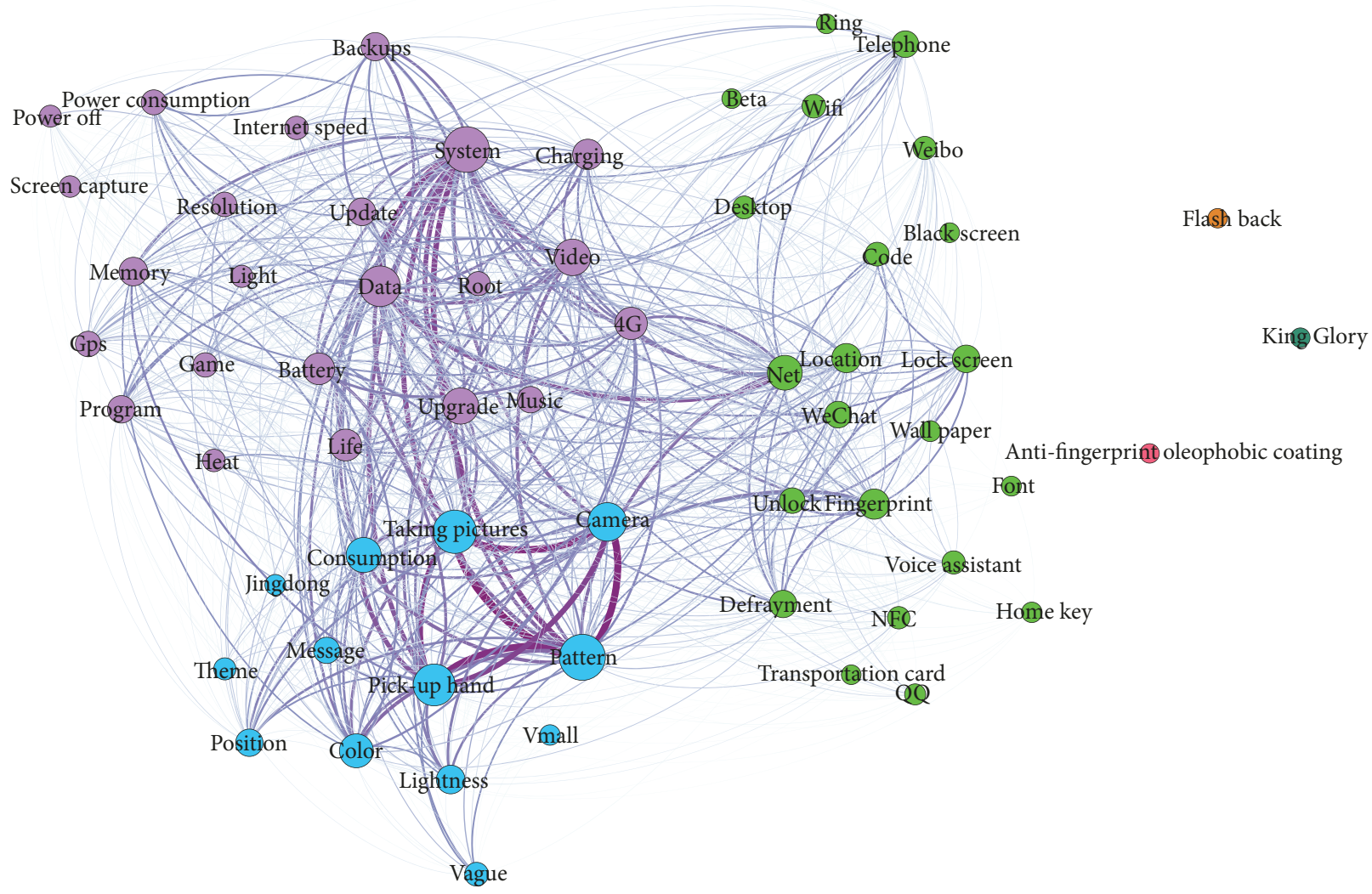

FIGURE 5: EUG interaction network.

the expectation of average degree is $E_{x}(G)=\sum_{i=1}^{n} d_{i} / n$, so variance of degree is

$$
\operatorname{Var}(G)=\frac{1}{n} \sum_{i=1}^{n}\left(d_{i}-E_{x}(G)\right)^{2}
$$

However, if $\mathrm{G}$ is an undirected weighted graph, variance of degree ignores the weight of edges' impact on the uniformity of G. As a result, this paper defines generalized variance of degree: if $n_{i}$ neighbors of node $i$ denotes $d_{i}^{g}$,

$$
d_{i}^{g}= \begin{cases}\sum_{l=1}^{n_{i}} w_{i}^{l} & n_{i}>0 \\ 0 & n_{i}=0\end{cases}
$$

where $w_{i}^{l}$ is the weight of link between node $i$ and its $l^{\text {th }}$ neighbor node, similarly the expectation of average of generalized degree is $G E_{x}(G)=\sum_{i=1}^{n} d_{i}^{g} / n$, and generalized variance of degree in network can be computed as follows:

$$
G \operatorname{Var}(G)=\frac{1}{n} \sum_{i=1}^{n}\left(d_{i}^{g}-G E_{x}(G)\right)^{2}
$$

This property is the general form of variance of degree, if $G$ is undirected unweighted graph generalized variance of degree degenerates as variance of degree, through calculating (3) and (5).
Moreover generalized variance of degree of its relative null model $G\left(V^{\prime}, E^{\prime}, W^{\prime}\right)$ is $G \operatorname{Var}(G)^{z e r o}$ and the standard deviation of $G\left(V^{\prime}, E^{\prime}, W^{\prime}\right)$ is $\sigma\left[G \operatorname{Var}(G)^{z e r o}\right]$. Since generalized variance of degree of $G\left(V^{\prime}, E^{\prime}, W^{\prime}\right)$ matches the $\mathrm{Z}$ distribution, in Appendix $\mathrm{C} \mathrm{Z}$ distribution is proved to approximate normal distribution. In this paper, "leader" network is defined as follows: if the generalized variance of degree of $\mathrm{G}$ is bigger than the " $3-\sigma$ " margin of null model $G\left(V^{\prime}, E^{\prime}, W^{\prime}\right)$; that is, $G \operatorname{Var}(G)>\operatorname{Mar}(G)=E\left[G \operatorname{Var}(G)^{\text {zero }}\right]+$ $3 \sigma\left[G \operatorname{Var}(G)^{\text {zero }}\right]$, or "autonomy" network otherwise. From this definition, "leader" network has significant nodes named "leaders" controlling other nodes and influencing the generalized variance of degree, however the importance of "autonomy" network is relatively even.

$G \operatorname{Var}(G)^{z e r o}$ may change every time along with the different result of random construction. If the generalized variance of degree of $p^{\text {th }}$ random result is $G \operatorname{Var}(G)^{\text {zero }}$, and there are $\mathrm{N}$ random graphs; then below forms

$$
\begin{gathered}
E\left[\frac{1}{N} \sum_{p=1}^{N} G \operatorname{Var}(G)_{p}^{\text {zero }}\right]=\frac{1}{N} \sum_{p=1}^{N} E\left[G \operatorname{Var}(G)_{p}^{\text {zero }}\right] \\
=\frac{1}{N} \sum_{p=1}^{N} E\left[G \operatorname{Var}(G)^{z e r o}\right]=E\left[G \operatorname{Var}(G)^{z e r o}\right]
\end{gathered}
$$

From this equation, it shows that a large number of generalized variance of random networks can be computed 
TABLE 3: Statistical results of three networks.

\begin{tabular}{lccccccc}
\hline Group name & $\begin{array}{c}\text { Average } \\
\text { degree }\end{array}$ & Density of graph & $\begin{array}{c}\text { Diameter of } \\
\text { graph }\end{array}$ & $\begin{array}{c}\text { Average clustering } \\
\text { coefficient }\end{array}$ & Modularity & $\begin{array}{c}\text { Density of isolated } \\
\text { nodes }\end{array}$ & $\begin{array}{c}\text { Generalized } \\
\text { variance of } \\
\text { degree of network }\end{array}$ \\
\hline OUG & 57.705 & 0.962 & 2 & 0.971 & 0.150 & $0.00 \%$ & 7620144.613 \\
IUG & 33.902 & 0.565 & 3 & 0.840 & 0.083 & $1.64 \%$ & 265766.736 \\
EUG & 32.492 & 0.542 & 3 & 0.827 & 0.140 & $4.92 \%$ & 15014.359 \\
\hline
\end{tabular}

TABLE 4: The results of null models.

\begin{tabular}{lcccccc}
\hline Group name & Average degree & Density of graph & $\begin{array}{c}\text { Diameter of } \\
\text { graph }\end{array}$ & $\begin{array}{c}\text { Average clustering } \\
\text { coefficient }\end{array}$ & $\begin{array}{c}\text { Density of isolated } \\
\text { nodes }\end{array}$ & $\begin{array}{c}\text { Generalized variance } \\
\text { of degree of network }\end{array}$ \\
\hline OUG & 60 & 1 & 1 & 1 & $0.00 \%$ & 2977.656 \\
IUG & 60 & 1 & 1 & 1 & $0.00 \%$ & 566.147 \\
EUG & 60 & 1 & 1 & 1 & $0.00 \%$ & 136.826 \\
\hline
\end{tabular}

to get the expectation of it. When $\mathrm{N}$ is relatively big, the mean of generalized variance of random networks of $\mathrm{N}$ random graphs can approximate $E\left[G \operatorname{Var}(G)^{\text {zero }}\right]$.

4.3. Comparison Analysis. The numerical result of 5 traditional properties showed in Section 4.2 (1)-(5) and 2 initiative ones are displayed in Table 3:

From OUG to IUG and EUG, in terms of the average degree, the relationships among topics decrease gradually. The density of them changes from great density to sparseness. Especially the proportion of from isolated topics and Figures $3-5$, there is no isolated topic in OUG but an isolated topic "GPS" in IUG and three in EUG including "King Glory," "Anti-fingerprint oleophobic coating," and "Flash back." This shows that the IUG solves three problems of ordinary users through interaction, so three topics become isolated in the EUG network. However, IUG does not solve "GPS," so EUG makes relevant interpretation. In terms of diameter of graph, the OUG is more compact compared with other two networks, suggesting that users in OUG equally focus on topics not having a clear mind on their relation. The average clustering coefficient illustrates microstructure of three networks, because the IUG and EUG have content knowledge, reducing the number of unnecessary contact between topics. Modularity shows the rationality of the division of the communities of three networks. Generalized variance of degree of network indicates that all the three groups have some provocation opinions on the relations between the topics, some topics holding more attention compared with others. These topics with significant status are mined in Section 5.

\section{Information Mining of "Leaders"}

Fu et al. (2016) suggested that nodes, which hold great importance, having strong relationship with others in the network, are called "leaders" [72]. This paper also judges whether there are "leaders" in three networks by computing properties results with their corresponding null models respectively. Moreover, "leaders" and closeness of topics are analyzed via eigenvector centrality method.
5.1. Existence of "Leaders". Firstly, whether networks have "leaders" that are judged: 1000 random networks are established by Matlab programming according to each null model structure separately. The 6 properties of the 1000 random networks are as follows.

As it shows in Table 4, since the characteristics of the networks built in this article are: $W_{\text {all }}>n(n-1) / 2$, which results in the mean average degree of all random networks corresponding to three groups are 60. By comparing the results between Tables 3 and 4, it is found that their properties have a significant difference.

If the generalized variance of degree of OUG network, IUG network, and EUG network is denoted, respectively, by $G \operatorname{Var}_{O U G}, G \operatorname{Var}_{I U G}, G \operatorname{Var}_{E U G}$ and the margin value of their corresponding null models is denoted by $\mathrm{Mar}_{\mathrm{OUG}}, \mathrm{Mar}_{I U G}, \mathrm{Mar}_{E U G}$, the following results are obtained from computing: $G \operatorname{Var}_{\text {OUG }}=7620144.613 \gg \operatorname{Mar}_{\text {OUG }}=$ 4652.730, GVar $\operatorname{Var}_{I U G}=265766.736 \gg \operatorname{Mar}_{I U G}=$ 857.300, $G \operatorname{Var}_{E U G}=15014.359 \gg \operatorname{Mar}_{E U G}=211.174$. It shows that the generalized variance of degree of three networks is greater than " $3-\sigma$ " boundary of that of their null models. So the OUG network, IUG network, and EUG network are "leader" networks with significant "leaders." The "leaders" in these networks will be explored below.

5.2. Finding "Leaders" in Certain Network. After certifying networks with "leaders," this section will dig them out and analyze the closeness of topics by eigenvector knowledge.

Iranzo (2016) analyzed the financial ability of village [73], so the importance of topics is also calculated by this method in this section. The concept of eigenvector centrality is that the importance of every node in network is associated with the number and quality (importance) of its neighbor nodes.

The results of eigenvector of maximum eigenvalue of three networks are calculated and normalized by Matlab, denoting $x_{i}^{c}=x_{i} / \sum_{j=1}^{n} x_{j}$, shown in Appendix D. Fu et al. (2016) proposed that the top 10 percent of importance of all nodes are "leaders" [72] and there are 61 topics in this research, so the "leaders" of three networks are in Table 5.

From Appendix D and Table 5, it is obvious that there is a certain difference among the importance ranking of 
TABLE 5: "Leaders" of three networks.

\begin{tabular}{lc}
\hline Group name & Topics \\
\hline OUG & System, Pick-up hand, WeChat, Upgrade, Power consumption, Voice assistant \\
IUG & System, Data, Memory, Wallpaper, Location, Unlock \\
EUG & Memory, System, Taking pictures, Resolution, Data, Update \\
\hline
\end{tabular}

TABLE 6: Kendall coefficient test.

\begin{tabular}{|c|c|c|c|c|}
\hline Comparison groups & OUG vs IUG & IUG vs EUG & OUG vs EUG & Overall \\
\hline Kendall coefficient & 0.694 & 0.723 & 0.797 & 0.651 \\
\hline$P$ value & 0.025 & 0.013 & 0.002 & 0.001 \\
\hline
\end{tabular}

three networks topics and "leaders", which means that the interaction levels of users on website are different and cause the difference in core topics. Kendall coefficient test in nonparametric statistics are computed in Table 6 to see whether the rankings of topics importance of three groups are different or not.

From the results of Kendall coefficient, the overall consistency is relatively low. Moreover, in the comparisons between two among them, the consistency of ranking "OUG vs IUG" is lowest compared with other two pairs. And the highest consistency pair is "OUG vs EUG." From the results of $\mathrm{P}$ value in Table 6 , the Kendall coefficient is reliable under $5 \%$ significant level.

As is analyzed in the former part, EUG need to combine the feedback of IUG, for example, system version test and solution to the problems, with taste of OUG to issue content, so it has a relatively high consistence with OUG in ranking. However, the classification of topics of IUG makes it different from others.

In computing eigenvectors centrality progress, we can also get the maximum eigenvalue $\lambda_{1}$ of corresponding networks, which means the interaction intensity of the network. If the maximum eigenvalue of the OUG network, IUG network, and EUG, respectively, is denoted by $\lambda_{\mathrm{OUG}}, \lambda_{I U G}, \lambda_{E U G}$, the values of them are calculated: $\lambda_{\text {OUG }}=5651.53 \gg \lambda_{I U G}=$ $1045.26>\lambda_{E U G}=267.81$. From the maximum eigenvalues of the three networks, it is shown that the maximum eigenvalue gradually declines from the OUG to the IUG and then to the EUG. Because the OUG has $99 \%$ valid data, the maximum eigenvalue of the network is naturally large. However, the interaction effect of IUG network is better than that of the EUG network. This also proves that intermediary users have reduced the pressure of the EUG as the backbone.

5.3. Ranking Topics Based on Multiplex Network. Importance of topics in all groups is analyzed. However, three networks have overlapping topics. To get all topics that users concerned, that is, to discover the overall "leaders," three networks are overlapped effectively in this section and analyzed from the perspective of multiplex.

Firstly, the multiplex network is designed as follows. The bottom layer is the interaction network of OUG, the middle layer is the interaction network of IUG, and the top layer is the interaction network of EUG. Same topics in two adjacent layers are connected, getting Figure 6.
In Figure 6, the pink nodes represent isolated topics in the corresponding layer and the grey nodes are interactive topics. Larger nodes (topic name) reflect higher degree. Clearly, the IUG fails to solve "GPS" and thereby generates the isolated topics. However, these topics are absent in the isolated topics of interaction network of EUG, indicating that EUG solves problems beyond the competence of OUG and IUG. Similarly, three isolated topics in the interaction network of EUG are absent in the interaction network of IUG, which reflects that these three topics are solved by the IUG and the EUG does not need to explain them. In brief, the IUG, the bridge between the OUG and the EUG serves as the "problem filter" well. They enhance the ability of users to solve problems through interaction and relieve pressure of customer service of enterprises. This also reflects that stimulating the interaction between the IUG and the OUG can bring consumers fast updating in product experience.

Boccaletti et al. (2014) introduced the method of ranking of node importance based on multiplex network. If normalized eigenvector centrality of OUG network, IUG network, and EUG network is $\left(x_{1}^{c(i)}, x_{2}^{c(i)}, \ldots, x_{n}^{c(i)}\right)^{\tau}(i=1,2,3)$, then the $j^{\text {th }}(j=1,2, \ldots, n)$ node importance is defined below [74]:

$$
x_{j}^{c}=\sum_{i=1}^{3} x_{j}^{c(i)}
$$

By combining results in Appendix D and (7), the importance and its ranking of topics based on multiplex network are shown in Appendix E. "Leaders" in the multiplex network are "system," "memory," "camera," "data," "update," and "pixel." However, "Anti-fingerprint oleophobic coating," "King Glory," and "Fingerprint" are less correlated with other topics, indicating their less importance. These topics have certain difference in importance.

\section{Conclusions}

The consumer community network is explored in this paper by methodology and empirical study based on the data in Huawei P10/P10 Plus community. In methodology, interaction difference and uniformity within consumer community are explored by the density of isolated nodes and generalized variance of degree of network. In empirical studies, community network users are divided into OUG, IUG, and EUG 


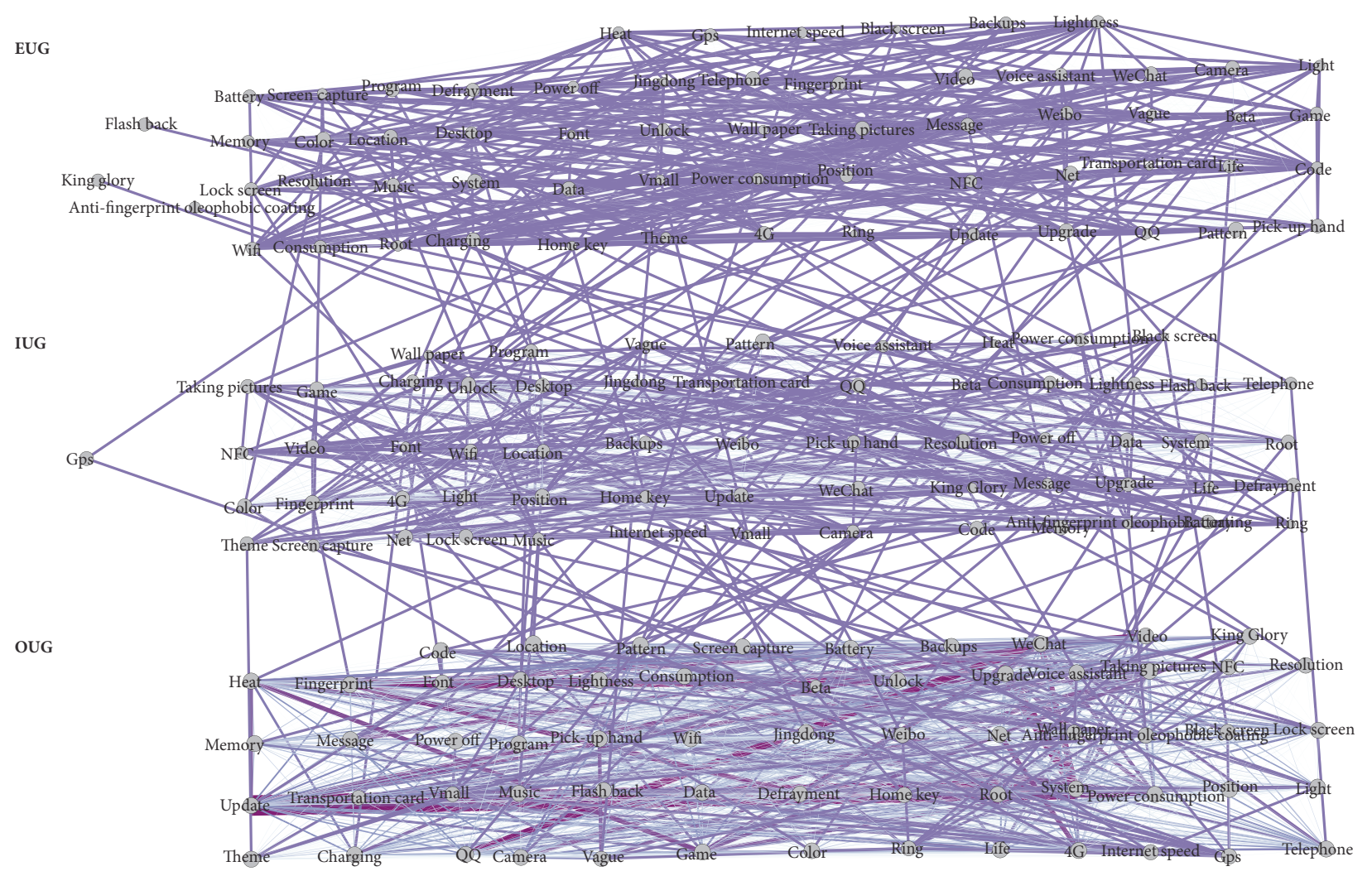

FIgURE 6: Consumer network based on multiplex network.

according to empirical data and corresponding interaction networks are constructed. A contrastive analysis on these three interaction networks is carried out by combining the existing properties and innovative properties. Topics in each network are put in the order according to significance.

Based on above studies, we conclude that consumer community network is the important place that reflects product experiences and facilitates product innovation in future. Manufacturers can promote improvement and innovation of products by exploring effective information on the consumer community network, thus improving the experience level of consumers. On this basis, three strategies to improve information mining in consumer community networks are proposed:

(1) Problems that users concerned are recognized by deep exploring and full understanding of post contents and themes as well as characteristics of cell phone. Problems could be classified reasonably (community division in the network) and core problems could be recognized by multiplex network, thus enabling to solve and guide users' problems in time.

(2) The IUG shall be encouraged and guided to improve the overall interaction performance in the community network. By analyzing the member structure of consumer community, the role of IUG as the bridge between OUG and EUG deserves attention. Enterprises encourage the IUG to interact with OUG and help them to solve problems. This can not only relieve pressure of enterprises in early counseling and late after-sale services but also guide users to improve self-management.
Moreover, enterprise group users shall make use of the key role of IUG in development and test of new products, collecting effective feedbacks quickly and shortening the launch time of new products.

\section{Appendix}

\section{A. The Frequency of Initial Tocpics}

See Table 7 .

\section{B. The Statistics of Valid Posts of Corresponding User and Group}

See Table 8.

\section{Norm Feature of Z Distribution}

Here, we, respectively, build null models of OUG network, IUG network, and EUG network, according to which 1000 random graphs are generated. And $\mathrm{Z}$ statistic is built for general variance of degrees of network, which is approximated to normal distribution proved by Kolmogorov-Smirnov test method, so that the "leader" network is determined by " $3-\sigma$ " boundary Mar.

Firstly, Z statistics of general variance of degrees of network is defined as follows:

$$
Z \triangleq \frac{G \operatorname{Var}(G)^{z e r o}-G E_{x}(G)}{\sigma\left[G \operatorname{Var}(G)^{z e r o}\right]}
$$




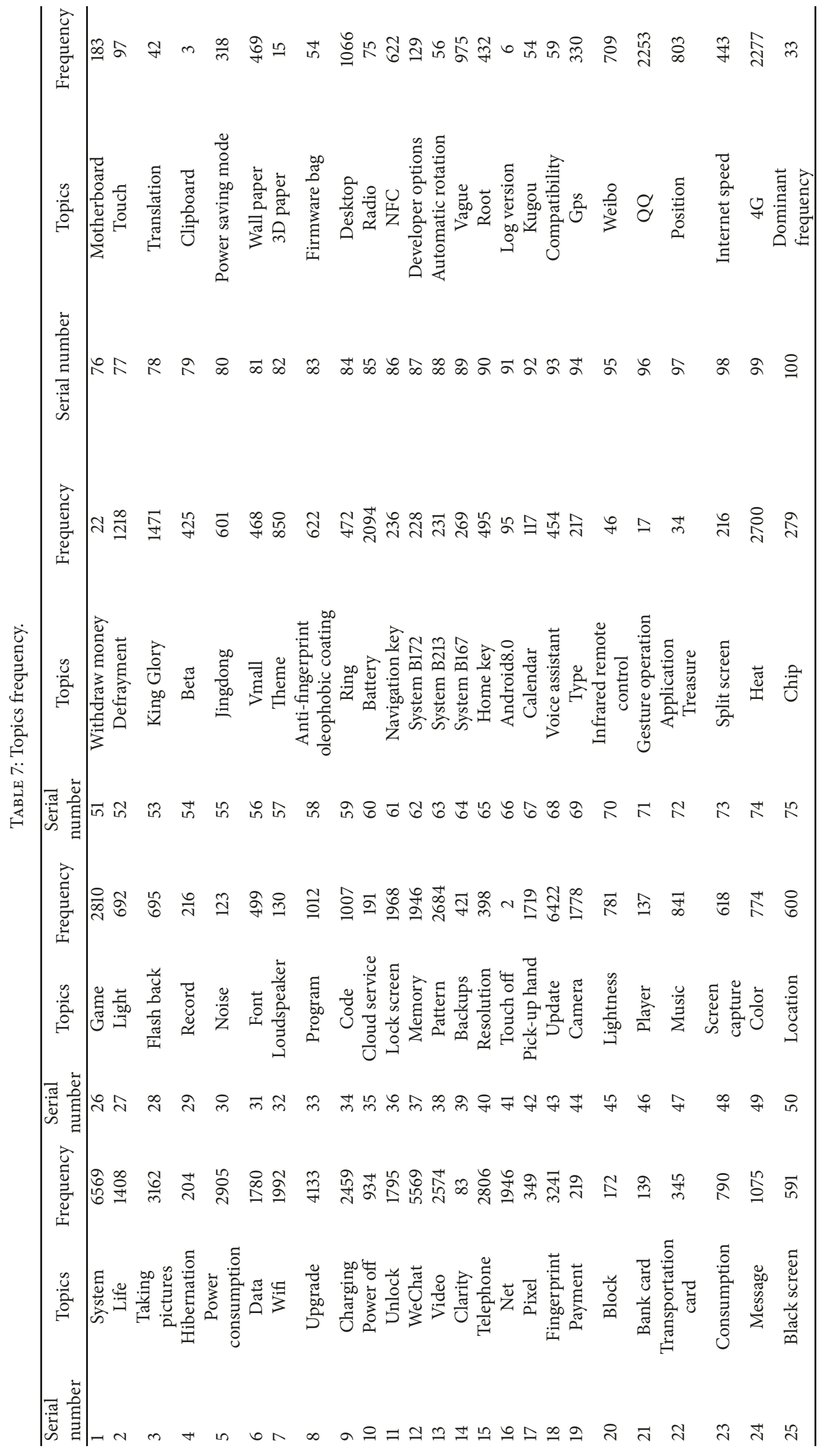


TABLE 8: Related statistics of valid posts of corresponding user.

\begin{tabular}{|c|c|c|c|c|}
\hline Group name & Level name & Number of posts & Frequency of the same group & Overall frequency \\
\hline \multirow{13}{*}{ OUG } & Newcome & 18556 & $24.14 \%$ & $23.94 \%$ \\
\hline & Beginners & 12562 & $16.34 \%$ & $16.21 \%$ \\
\hline & Preliminary learners & 17743 & $23.08 \%$ & $22.90 \%$ \\
\hline & Small success & 12578 & $16.36 \%$ & $16.23 \%$ \\
\hline & Further progress & 7546 & $9.81 \%$ & $9.74 \%$ \\
\hline & Master & 4591 & $5.97 \%$ & $5.92 \%$ \\
\hline & The dedicated & 2575 & $3.35 \%$ & $3.32 \%$ \\
\hline & The self-contained & 385 & $0.50 \%$ & $0.50 \%$ \\
\hline & Great success & 291 & $0.38 \%$ & $0.38 \%$ \\
\hline & Pinnacle & 47 & $0.06 \%$ & $0.06 \%$ \\
\hline & Magic master & 8 & $0.01 \%$ & $0.01 \%$ \\
\hline & The matchless & 1 & $0.00 \%$ & $0.00 \%$ \\
\hline & Limited member & 1 & $0.00 \%$ & $0.00 \%$ \\
\hline \multirow{14}{*}{ IUG } & Hot fans & 1 & $0.29 \%$ & $0.00 \%$ \\
\hline & Expert fans & 81 & $23.89 \%$ & $0.10 \%$ \\
\hline & Female fans & 1 & $0.29 \%$ & $0.00 \%$ \\
\hline & Internal manager & 2 & $0.59 \%$ & $0.00 \%$ \\
\hline & Internal expert & 16 & $4.72 \%$ & $0.02 \%$ \\
\hline & Pollen director of city & 9 & $2.65 \%$ & $0.01 \%$ \\
\hline & Pollen director of universities & 1 & $0.29 \%$ & $0.00 \%$ \\
\hline & Special forces of HPC & 21 & $6.19 \%$ & $0.03 \%$ \\
\hline & Moderator of HPC & 117 & $34.51 \%$ & $0.15 \%$ \\
\hline & Moderator of Huawei Pollen Sub-club & 8 & $2.36 \%$ & $0.01 \%$ \\
\hline & Moderator of game center & 1 & $0.29 \%$ & $0.00 \%$ \\
\hline & HRT team & 79 & $28.94 \%$ & $0.17 \%$ \\
\hline & Super-circle director of HPC & 1 & $0.37 \%$ & $0.00 \%$ \\
\hline & Theme fans & 1 & $0.37 \%$ & $0.01 \%$ \\
\hline \multirow{6}{*}{ EUG } & Pollen group & 134 & $49.08 \%$ & $0.00 \%$ \\
\hline & HPC team & 11 & $4.03 \%$ & $0.10 \%$ \\
\hline & Official team & 111 & $40.66 \%$ & $0.14 \%$ \\
\hline & EMIUI product manager & 3 & $1.10 \%$ & $0.00 \%$ \\
\hline & EMIUI official team & 5 & $1.83 \%$ & $0.01 \%$ \\
\hline & Product manager & 9 & $3.30 \%$ & $0.01 \%$ \\
\hline
\end{tabular}

where $G \operatorname{Var}(G)^{\text {zero }}$ is a random variable of general variance of degrees of random network, with $\sigma\left[G \operatorname{Var}(G)^{z e r o}\right]$ standard deviation of $G \operatorname{Var}(G)^{\text {zero }}$ and $G E_{x}(G)$ the average value of $G \operatorname{Var}(G)^{\text {zero }}$.

We calculate the general variance of degrees of 1000 random graphs of the OUG network, IUG network, and EUG network. Figures 7-9 show the frequency distribution histogram.

In Figures 7-9, lines represent the normal distribution curve fitting according to the mean and standard deviation of frequency of general variance of degrees of network. And histograms of the three groups of corresponding null models are bell shaped. In order to test whether the distribution of general variance of degrees of null models conform to normal distribution, the K-S test method results are as in Table 9.

From Table 9, we can see that considering norm curve fitting of general variance of degrees' frequency, their
TABLE 9: Kolmogorov-Smirnov test.

\begin{tabular}{lcc}
\hline Group name & Kolmogorov-Smirnov value & P value \\
\hline OUG & 1.202 & 0.111 \\
IUG & 0.927 & 0.356 \\
EUG & 1.019 & 0.250 \\
\hline
\end{tabular}

Kolmogorov-Smirnov values are all significantly greater than 0.05 , indicating that the distribution of general variance of degrees of random networks can approximate normal distribution; that is, $Z \sim N(0,1)$. Moreover, the " $3 \sigma$ " boundary of $G$ denotes $\operatorname{Mar}(G)$, which can be calculated through the following form:

$$
\operatorname{Mar}(G)=E\left[G \operatorname{Var}(G)^{z e r o}\right]+3 \sigma\left[G \operatorname{Var}(G)^{\text {zero }}\right]
$$


TABLE 10: The importance ranking and eigenvector corresponding to maximum eigenvalue of three networks.

\begin{tabular}{|c|c|c|c|c|c|c|}
\hline Hot topics & $\begin{array}{l}\text { Eigenvector } \\
\text { of OUG }\end{array}$ & $\begin{array}{c}\text { Importance } \\
\text { ranking of } \\
\text { topics of } \\
\text { OUG }\end{array}$ & $\begin{array}{l}\text { Eigenvector } \\
\text { of IUG) }\end{array}$ & $\begin{array}{l}\text { Importance } \\
\text { ranking of } \\
\text { topics of IUG }\end{array}$ & $\begin{array}{l}\text { Eigenvector of } \\
\text { EUG }\end{array}$ & $\begin{array}{l}\text { Importance } \\
\text { ranking of } \\
\text { topics of EUG }\end{array}$ \\
\hline System & $7.97 \%$ & 1 & $4.66 \%$ & 1 & $5.62 \%$ & 2 \\
\hline Life & $2.18 \%$ & 19 & $0.19 \%$ & 46 & $2.65 \%$ & 13 \\
\hline Taking pictures & $2.89 \%$ & 9 & $0.81 \%$ & 35 & $5.12 \%$ & 3 \\
\hline Power consumption & $3.87 \%$ & 5 & $2.87 \%$ & 15 & $1.20 \%$ & 32 \\
\hline Data & $1.89 \%$ & 21 & $4.26 \%$ & 2 & $4.55 \%$ & 5 \\
\hline Wifi & $2.31 \%$ & 14 & $3.72 \%$ & 10 & $0.91 \%$ & 38 \\
\hline Upgrade & $4.73 \%$ & 4 & $1.15 \%$ & 32 & $3.59 \%$ & 8 \\
\hline Charging & $2.29 \%$ & 16 & $0.38 \%$ & 42 & $2.35 \%$ & 15 \\
\hline Power off & $0.93 \%$ & 30 & $2.13 \%$ & 24 & $0.52 \%$ & 47 \\
\hline Unlock & $1.96 \%$ & 20 & $4.12 \%$ & 6 & $1.31 \%$ & 30 \\
\hline WeChat & $5.52 \%$ & 3 & $0.76 \%$ & 37 & $1.54 \%$ & 27 \\
\hline Video & $2.75 \%$ & 10 & $0.18 \%$ & 47 & $3.67 \%$ & 7 \\
\hline Telephone & $2.30 \%$ & 15 & $1.88 \%$ & 26 & $1.55 \%$ & 26 \\
\hline Net & $2.24 \%$ & 17 & $2.34 \%$ & 20 & $3.29 \%$ & 10 \\
\hline Fingerprint & $3.17 \%$ & 8 & $3.56 \%$ & 11 & $2.31 \%$ & 16 \\
\hline Transportation card & $0.12 \%$ & 61 & $0.04 \%$ & 54 & $0.03 \%$ & 58 \\
\hline Consumption & $0.74 \%$ & 38 & $0.30 \%$ & 43 & $3.35 \%$ & 9 \\
\hline Message & $1.43 \%$ & 28 & $0.06 \%$ & 50 & $1.46 \%$ & 29 \\
\hline Black screen & $0.66 \%$ & 41 & $0.01 \%$ & 57 & $0.06 \%$ & 55 \\
\hline Game & $3.52 \%$ & 7 & $3.42 \%$ & 12 & $1.06 \%$ & 34 \\
\hline Light & $0.66 \%$ & 42 & $0.26 \%$ & 45 & $0.56 \%$ & 46 \\
\hline Flash back & $0.72 \%$ & 39 & $1.12 \%$ & 33 & $0.00 \%$ & 59 \\
\hline Font & $0.32 \%$ & 55 & $0.07 \%$ & 49 & $0.08 \%$ & 54 \\
\hline Program & $1.26 \%$ & 29 & $3.00 \%$ & 14 & $1.71 \%$ & 23 \\
\hline Code & $0.86 \%$ & 33 & $3.31 \%$ & 13 & $0.93 \%$ & 36 \\
\hline Lock screen & $1.85 \%$ & 22 & $2.72 \%$ & 17 & $1.74 \%$ & 22 \\
\hline Memory & $1.59 \%$ & 26 & $2.60 \%$ & 18 & $1.97 \%$ & 19 \\
\hline Pattern & $2.64 \%$ & 12 & $4.22 \%$ & 3 & $5.71 \%$ & 1 \\
\hline Backups & $0.40 \%$ & 52 & $3.95 \%$ & 9 & $1.88 \%$ & 20 \\
\hline Resolution & $0.60 \%$ & 44 & $2.52 \%$ & 19 & $1.09 \%$ & 33 \\
\hline Pick-up hand & $1.51 \%$ & 27 & $0.70 \%$ & 39 & $4.81 \%$ & 4 \\
\hline Update & $6.64 \%$ & 2 & $4.04 \%$ & 7 & $1.75 \%$ & 21 \\
\hline Camera & $1.73 \%$ & 23 & $0.27 \%$ & 44 & $4.09 \%$ & 6 \\
\hline Lightness & $0.88 \%$ & 32 & $1.91 \%$ & 25 & $1.97 \%$ & 18 \\
\hline Music & $0.78 \%$ & 36 & $0.77 \%$ & 36 & $1.49 \%$ & 28 \\
\hline Screen capture & $0.44 \%$ & 49 & $2.31 \%$ & 21 & $0.45 \%$ & 48 \\
\hline Color & $0.61 \%$ & 43 & $2.21 \%$ & 23 & $3.10 \%$ & 11 \\
\hline Location & $0.70 \%$ & 40 & $1.30 \%$ & 29 & $2.09 \%$ & 17 \\
\hline Defrayment & $1.63 \%$ & 25 & $1.31 \%$ & 28 & $1.70 \%$ & 25 \\
\hline King Glory & $1.64 \%$ & 24 & $0.50 \%$ & 40 & $0.00 \%$ & 59 \\
\hline Beta & $0.32 \%$ & 54 & $0.00 \%$ & 60 & $0.04 \%$ & 57 \\
\hline Jingdong & $0.43 \%$ & 50 & $0.01 \%$ & 58 & $0.27 \%$ & 51 \\
\hline Vmall & $0.24 \%$ & 60 & $0.01 \%$ & 58 & $0.22 \%$ & 52 \\
\hline Theme & $0.43 \%$ & 51 & $1.16 \%$ & 31 & $0.57 \%$ & 45 \\
\hline Anti-fingerprint oleophobic coating & $0.49 \%$ & 47 & $0.05 \%$ & 52 & $0.00 \%$ & 59 \\
\hline
\end{tabular}


TABle 10: Continued.

\begin{tabular}{|c|c|c|c|c|c|c|}
\hline Hot topics & $\begin{array}{c}\text { Eigenvector } \\
\text { of OUG }\end{array}$ & $\begin{array}{c}\text { Importance } \\
\text { ranking of } \\
\text { topics of } \\
\text { OUG } \\
\end{array}$ & $\begin{array}{l}\text { Eigenvector } \\
\text { of IUG) }\end{array}$ & $\begin{array}{l}\text { Importance } \\
\text { ranking of } \\
\text { topics of IUG }\end{array}$ & $\begin{array}{c}\text { Eigenvector of } \\
\text { EUG }\end{array}$ & $\begin{array}{l}\text { Importance } \\
\text { ranking of } \\
\text { topics of EUG }\end{array}$ \\
\hline Ring & $0.32 \%$ & 56 & $0.05 \%$ & 51 & $0.06 \%$ & 56 \\
\hline Battery & $2.64 \%$ & 11 & $2.25 \%$ & 22 & $2.63 \%$ & 14 \\
\hline Home key & $0.50 \%$ & 46 & $0.42 \%$ & 41 & $0.21 \%$ & 53 \\
\hline Voice assistant & $0.28 \%$ & 58 & $1.83 \%$ & 27 & $0.80 \%$ & 40 \\
\hline Heat & $3.54 \%$ & 6 & $0.01 \%$ & 55 & $0.66 \%$ & 43 \\
\hline Wall paper & $0.28 \%$ & 59 & $0.12 \%$ & 48 & $0.31 \%$ & 50 \\
\hline Desktop & $0.81 \%$ & 35 & $4.17 \%$ & 4 & $0.73 \%$ & 42 \\
\hline NFC & $0.36 \%$ & 53 & $1.22 \%$ & 30 & $0.63 \%$ & 44 \\
\hline Vague & $0.90 \%$ & 31 & $0.04 \%$ & 53 & $0.92 \%$ & 37 \\
\hline Root & $0.31 \%$ & 57 & $4.02 \%$ & 8 & $0.99 \%$ & 35 \\
\hline GPS & $0.45 \%$ & 48 & $0.00 \%$ & 61 & $1.29 \%$ & 31 \\
\hline Weibo & $0.82 \%$ & 34 & $1.02 \%$ & 34 & $0.80 \%$ & 41 \\
\hline QQ & $2.50 \%$ & 13 & $0.74 \%$ & 38 & $0.35 \%$ & 49 \\
\hline Position & $0.74 \%$ & 37 & $4.16 \%$ & 5 & $1.70 \%$ & 24 \\
\hline Internet speed & $0.52 \%$ & 45 & $0.01 \%$ & 56 & $0.85 \%$ & 39 \\
\hline $4 \mathrm{G}$ & $2.18 \%$ & 18 & $2.80 \%$ & 16 & $2.76 \%$ & 12 \\
\hline
\end{tabular}

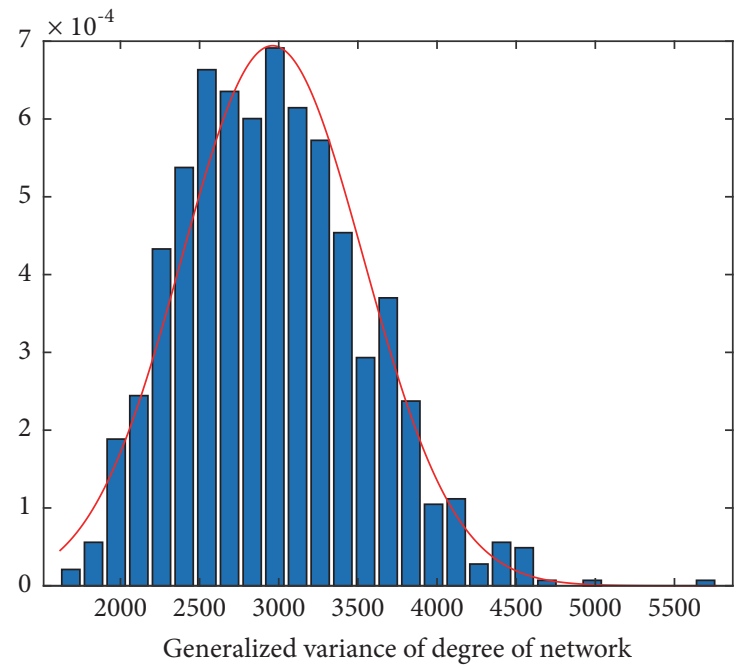

— Normal distribution fitting curve

FIGURE 7: Generalized variance of degree of network of null model of OUG.

Based on the " $3 \sigma$ " principle in statistics, there is a significant difference between $\mathrm{G}$ and the corresponding null model, if $G \operatorname{Var}(G)>\operatorname{Mar}(G)$. As a result, the network $\mathrm{G}$ is a "leader" network with uneven importance nodes.

\section{The Importance of Topics in Three Networks}

See Table 10.

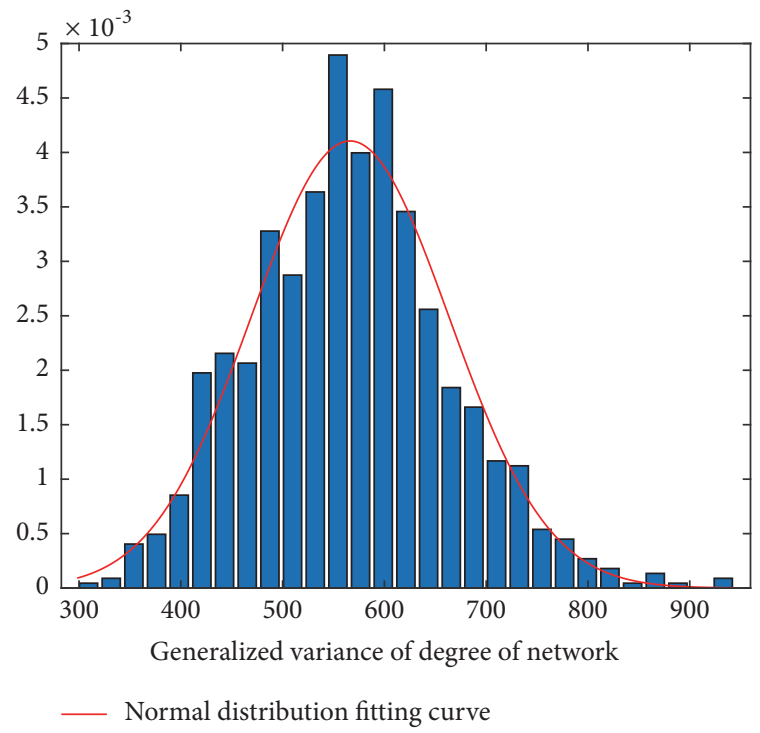

FIGURE 8: Generalized variance of degree of network of null model of IUG.

\section{E. The Importance of Topics in Multiplex Netwok}

See Table 11.

\section{Data Availability}

The Huawei P10/P10 Plus data used to support the findings of this study are available from the corresponding author upon request. 
TABLE 11: The importance and its ranking of topics based on multiplex network.

\begin{tabular}{|c|c|c|}
\hline Hot topics & $\begin{array}{l}\text { Importance of topics in } \\
\text { multiplex network }\end{array}$ & $\begin{array}{c}\text { Ranking of topics } \\
\text { importance }\end{array}$ \\
\hline System & $18.25 \%$ & 1 \\
\hline Memory & $12.57 \%$ & 2 \\
\hline Pick-up hand & $12.43 \%$ & 3 \\
\hline Data & $10.70 \%$ & 4 \\
\hline Upgrade & $9.46 \%$ & 5 \\
\hline Pixel & $9.04 \%$ & 6 \\
\hline Taking pictures & $8.81 \%$ & 7 \\
\hline Black screen & $8.00 \%$ & 8 \\
\hline Power consumption & $7.95 \%$ & 9 \\
\hline Net & $7.87 \%$ & 10 \\
\hline WeChat & $7.82 \%$ & 11 \\
\hline $4 \mathrm{G}$ & $7.74 \%$ & 12 \\
\hline Ring & $7.52 \%$ & 13 \\
\hline Unlock & $7.39 \%$ & 14 \\
\hline Resolution & $7.02 \%$ & 15 \\
\hline Wifi & $6.94 \%$ & 16 \\
\hline Position & $6.60 \%$ & 17 \\
\hline Video & $6.60 \%$ & 18 \\
\hline Code & $6.31 \%$ & 19 \\
\hline Pattern & $6.22 \%$ & 20 \\
\hline Lock screen & $6.16 \%$ & 21 \\
\hline Update & $6.09 \%$ & 22 \\
\hline Font & $5.98 \%$ & 23 \\
\hline Screen capture & $5.93 \%$ & 24 \\
\hline Telephone & $5.72 \%$ & 25 \\
\hline Wall paper & $5.70 \%$ & 26 \\
\hline Vague & $5.31 \%$ & 27 \\
\hline Program & $5.10 \%$ & 28 \\
\hline Life & $5.02 \%$ & 29 \\
\hline Charging & $5.02 \%$ & 30 \\
\hline Camera & $4.76 \%$ & 31 \\
\hline Location & $4.64 \%$ & 32 \\
\hline Transportation card & $4.38 \%$ & 33 \\
\hline Voice assistant & $4.21 \%$ & 34 \\
\hline Backups & $4.20 \%$ & 35 \\
\hline Color & $4.10 \%$ & 36 \\
\hline QQ & $3.59 \%$ & 37 \\
\hline Power off & $3.58 \%$ & 38 \\
\hline Music & $3.20 \%$ & 39 \\
\hline Lightness & $3.03 \%$ & 40 \\
\hline Consumption & $2.96 \%$ & 41 \\
\hline Home key & $2.91 \%$ & 42 \\
\hline Weibo & $2.64 \%$ & 43 \\
\hline Desktop & $2.21 \%$ & 44 \\
\hline Vmall & $2.15 \%$ & 45 \\
\hline Defrayment & $2.14 \%$ & 46 \\
\hline NFC & $1.86 \%$ & 47 \\
\hline Light & $1.84 \%$ & 48 \\
\hline Root & $1.75 \%$ & 49 \\
\hline Game & $1.49 \%$ & 50 \\
\hline Internet speed & $1.38 \%$ & 51 \\
\hline Battery & $1.13 \%$ & 52 \\
\hline Message & $0.73 \%$ & 53 \\
\hline Beta & $0.71 \%$ & 54 \\
\hline Heat & $0.70 \%$ & 55 \\
\hline
\end{tabular}

TABLE 11: Continued.

\begin{tabular}{lcc}
\hline Hot topics & $\begin{array}{c}\text { Importance of topics in } \\
\text { multiplex network }\end{array}$ & $\begin{array}{c}\text { Ranking of topics } \\
\text { importance }\end{array}$ \\
\hline Theme & $0.54 \%$ & 56 \\
Flash back & $0.47 \%$ & 57 \\
Jingdong & $0.46 \%$ & 58 \\
Anti-fingerprint & $0.42 \%$ & 59 \\
oleophobic coating & $0.36 \%$ & 60 \\
King Glory & $0.19 \%$ & 61 \\
Fingerprint & & \\
\hline
\end{tabular}

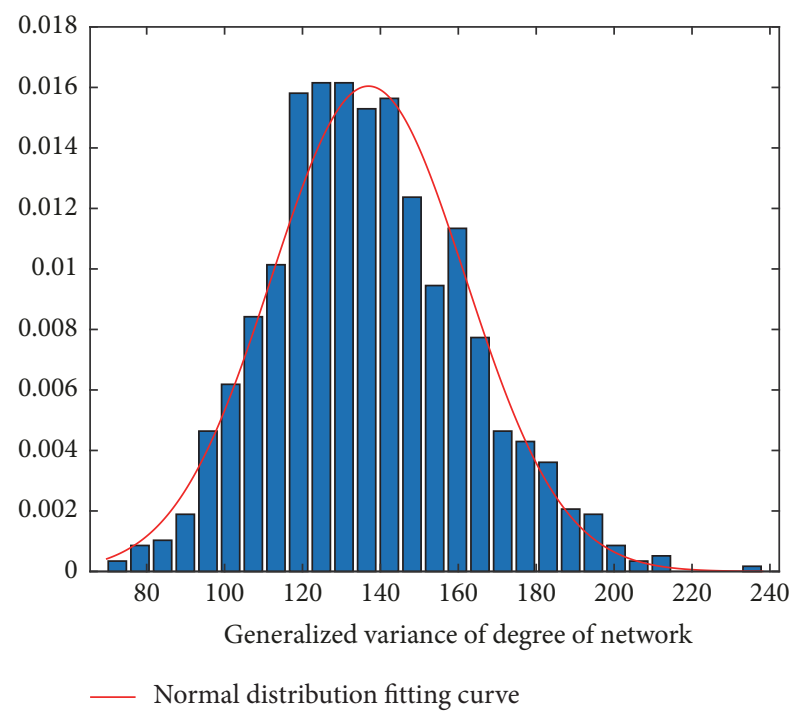

FIGURE 9: Generalized variance of degree of network of null model of EUG.

\section{Disclosure}

Qingchun Meng and Zhen Zhang are co-first authors on this work.

\section{Conflicts of Interest}

The authors declare that there are no conflicts of interest regarding the publication of this paper.

\section{Authors' Contributions}

Qingchun Meng and Zhen Zhang contributed equally to this work.

\section{Acknowledgments}

This study is supported by the National Nature Science Foundation of China (NSFC) (Grant no. 71572096).

\section{References}

[1] S. Boccaletti, V. Latora, Y. Moreno, M. Chavez, and D. W. Hwang, "Complex networks: Structure and dynamics," Physics Reports, vol. 424, no. 4-5, pp. 175-308, 2006. 
[2] M. E. J. Newman, "The structure and function of complex networks," SIAM Review, vol. 45, no. 2, pp. 167-256, 2003.

[3] M. E. J. Newman, Networks: An Introduction, Oxford University Press, Oxford, UK, 2010.

[4] S. Dealy, S. Kauffman, and J. Socolar, "Modeling pathways of differentiation in genetic regulatory networks with Boolean networks," Complexity, vol. 11, no. 1, pp. 52-60, 2005.

[5] T. Toulouse, P. Ao, I. Shmulevich, and S. Kauffman, "Noise in a small genetic circuit that undergoes bifurcation," Complexity, vol. 11, no. 1, pp. 45-51, 2005.

[6] M. Gherardi and P. Rotondo, "Measuring logic complexity can guide pattern discovery in empirical systems," Complexity, vol. 21, no. S2, pp. 397-408, 2016.

[7] C. Castellano, S. Fortunato, and V. Loreto, "Statistical physics of social dynamics," Reviews of Modern Physics, vol. 81, no. 2, pp. 591-646, 2009.

[8] D. Centola, "The spread of behavior in an online social network experiment," Science, vol. 329, no. 5996, pp. 1194-1197, 2010.

[9] K. Lewis, J. Kaufman, M. Gonzalez, A. Wimmer, and N. Christakis, "Tastes, ties, and time: A new social network dataset using Facebook.com," Social Networks, vol. 30, no. 4, pp. 330342, 2008.

[10] S. G. B. Roberts, R. I. M. Dunbar, T. V. Pollet, and T. Kuppens, "Exploring variation in active network size: Constraints and ego characteristics," Social Networks, vol. 31, no. 2, pp. 138-146, 2009.

[11] Y. E. Riyanto and Y. X. W. Jonathan, "Directed trust and trustworthiness in a social network: An experimental investigation," Journal of Economic Behavior Organization, vol. 151, pp. 234253, 2018.

[12] J. Shim and J. Kim, "Estimating country-level social network density and supportive surroundings by simulation," Journal of Business Venturing Insights, vol. 9, pp. 24-31, 2018.

[13] N. Sumith, B. Annappa, and S. Bhattacharya, "Social network pruning for building optimal social network: A user perspective," Knowledge-Based Systems, vol. 117, pp. 101-110, 2017.

[14] J. F. Houston, J. Lee, and F. Suntheim, "Social networks in the global banking sector," Journal of Accounting and Economics, 2017.

[15] Z. Qiu and H. Shen, "User clustering in a dynamic social network topic model for short text streams," Information Sciences, vol. 414, pp. 102-116, 2017.

[16] M. Fu, H. Yang, J. Feng et al., "Preferential information dynamics model for online social networks," Physica A: Statistical Mechanics and its Applications, vol. 506, pp. 993-1005, 2018.

[17] A. Röper, B. Völker, and H. Flap, "Social networks and getting a home: Do contacts matter?" Social Networks, vol. 31, no. 1, pp. 40-51, 2009.

[18] Y. Hu, M. Aiello, and C. Hu, "Information diffusion in online social networks: A compilation," Journal of Computational Science, vol. 28, pp. 204-205, 2018.

[19] N. Zhang and W. Zhao, "Privacy-preserving data mining systems," The Computer Journal, vol. 40, no. 4, pp. 52-58, 2007.

[20] A. Cetto, M. Klier, A. Richter, and J. F. Zolitschka, ““Thanks for sharing"-Identifying users' roles based on knowledge contribution in Enterprise Social Networks," Computer Networks, vol. 135, pp. 275-288, 2018.

[21] H. K. Crabb, J. L. Allen, J. M. Devlin, S. M. Firestone, M. A. Stevenson, and J. R. Gilkerson, "The use of social network analysis to examine the transmission of Salmonella spp. within a vertically integrated broiler enterprise," Food Microbiology, vol. 71, pp. 73-81, 2018.
[22] B. Simpson and T. McGrimmon, "Trust and embedded markets: A multi-method investigation of consumer transactions," Social Networks, vol. 30, no. 1, pp. 1-15, 2008.

[23] X. L. Wan, Z. Zhang, X. X. Rong, and Q. C. Meng, "Exploring an interactive value-adding data-driven model of consumer electronics supply chain based on least squares support vector machine," Scientific Programming, vol. 2016, no. 8, Article ID 3717650, p. 13, 2016.

[24] A. Garas and A. Lapatinas, "The role of consumer networks in firms' multi-characteristics competition and market share inequality," Structural Change and Economic Dynamics, vol. 43, pp. 76-86, 2017.

[25] J. Ortiz, W.-H. Chih, and F.-S. Tsai, "Information privacy, consumer alienation, and lurking behavior in social networking sites," Computers in Human Behavior, vol. 80, pp. 143-157, 2018.

[26] M. Alonso-Dos-Santos, F. Rejón Guardia, C. Pérez Campos, F. Calabuig-Moreno, and Y. J. Ko, "Engagement in sports virtual brand communities," Journal of Business Research, vol. 89, pp. 273-279, 2018.

[27] Y. Xiong, Z. Cheng, E. Liang, and Y. Wu, "Accumulation mechanism of opinion leaders' social interaction ties in virtual communities: Empirical evidence from China," Computers in Human Behavior, vol. 82, pp. 81-93, 2018.

[28] J. C. Healy and P. McDonagh, "Consumer roles in brand culture and value co-creation in virtual communities," Journal of Business Research, vol. 66, no. 9, pp. 1528-1540, 2013.

[29] M. Katz, R. M. Ward, and B. Heere, "Explaining attendance through the brand community triad: Integrating network theory and team identification," Sport Management Review, vol. 21, no. 2, pp. 176-188, 2017.

[30] Anonymous, "Research on the product marketing strategies of clothing e-commercial enterprises based on customer experience," China Textile Leader, vol. 11, pp. 89-91, 2014.

[31] M.-H. Hsiao and L.-C. Chen, "Smart phone demand: An empirical study on the relationships between phone handset, Internet access and mobile services," Telematics and Informatics, vol. 32, no. 1, pp. 158-168, 2014.

[32] A. Paiano, G. Lagioia, and A. Cataldo, "A critical analysis of the sustainability of mobile phone use," Resources, Conservation \& Recycling, vol. 73, pp. 162-171, 2013.

[33] C.-H. Wang, "Incorporating the concept of systematic innovation into quality function deployment for developing multifunctional smart phones," Computers \& Industrial Engineering, vol. 107, pp. 367-375, 2017.

[34] IDC, IDC: Smartphone Vendor Market Share, IDC, 2018, https://www.idc.com/promo/smartphone-market-share/ vendor.

[35] Huawei Pollen Club, Huawei Pollen Club Forum: Huawei P10/P10 Plus Area, 2018, https://cn.club.vmall.com/forum2827-1.html.

[36] Huawei Pollen Club, Huawei Pollen Club Forum: Huawei P20 Area, 2018, https://cn.club.vmall.com/forum-3350-1.html.

[37] Huawei Pollen Club, Huawei Pollen Club Forum: Huawei Mate 10 Area, Huawei Pollen Club, 2018, https://cn.club.vmall.com/ forum-3065-1.html.

[38] N. Hajli, M. Shanmugam, S. Papagiannidis, D. Zahay, and M.-O. Richard, "Branding co-creation with members of online brand communities," Journal of Business Research, vol. 70, pp. 136-144, 2017.

[39] D. Georgi and M. Mink, "ECCIq: The quality of electronic customer-to-customer interaction," Journal of Retailing and Consumer Services, vol. 20, no. 1, pp. 11-19, 2013. 
[40] R. Smaliukiene, L. Chi-Shiun, and I. Sizovaite, "Consumer value co-creation in online business: the case of global travel services," Journal of Business Economics and Management, vol. 16, no. 2, pp. 325-339, 2015.

[41] M. Bruhn, S. Schnebelen, and D. Schäfer, "Antecedents and consequences of the quality of e-customer-to-customer interactions in B2B brand communities," Industrial Marketing Management, vol. 43, no. 1, pp. 164-176, 2014.

[42] C. Llinares Millán, D. Garzon, and S. Navarro, "C2C interactions creating value in the Route of Santiago," Journal of Business Research, vol. 69, no. 11, pp. 5448-5455, 2016.

[43] W. Wei, Y. Lu, L. Miao, L. A. Cai, and C.-Y. Wang, "Customercustomer interactions (CCIs) at conferences: An identity approach," Tourism Management, vol. 59, pp. 154-170, 2017.

[44] Y. Chen and H. Zhang, "The impact of customer to customer interaction on service company-customer relationship quality," in Proceedings of the 8th International Conference on Service Systems and Service Management, ICSSSM'11, vol. 11, China, June 2011.

[45] J. S. Oh, J. I. Shin, D. Y. Jeong, and K. H. Chung, “The effects of message directionality and brand image's level on consumer attitude," ICIC Express Letters, Part B: Applications, vol. 6, no. 4, pp. 1003-1008, 2015.

[46] R. Zollet and A. Back, "Critical factors influencing diffusion of interactivity innovations on corporate websites," IEEE Transactions on Professional Communication, vol. 58, no. 1, pp. 2-19, 2015.

[47] I. Khan, H. Dongping, and A. Wahab, "Does culture matter in effectiveness of social media marketing strategy? An investigation of brand fan pages," Aslib Journal of Information Management, vol. 68, no. 6, pp. 694-715, 2016.

[48] H. Nourikhah and M. K. Akbari, "Impact of service quality on user satisfaction: Modeling and estimating distribution of quality of experience using Bayesian data analysis," Electronic Commerce Research and Applications, vol. 17, pp. 112-122, 2016.

[49] S. Shobeiri, E. Mazaheri, and M. Laroche, "How customers respond to the assistive intent of an E-retailer?" International Journal of Retail \& Distribution Management, vol. 42, no. 5, pp. 369-389, 2014.

[50] D.-K. Liou, L.-C. Hsu, and W.-H. Chih, "Understanding broadband television users' continuance intention to use," Industrial Management \& Data Systems, vol. 115, no. 2, pp. 210-234, 2015.

[51] J. Islam and Z. Rahman, "The impact of online brand community characteristics on customer engagement: An application of Stimulus-Organism-Response paradigm," Telematics and Informatics, vol. 34, no. 4, pp. 96-109, 2017.

[52] M. Kilgour, S. L. Sasser, and R. Larke, "The social media transformation process: Curating content into strategy," Corporate Communications, vol. 20, no. 3, pp. 326-343, 2015.

[53] S. McKechnie and P. Nath, "Effects of new-to-market e-store features on first time browsers," International Journal of HumanComputer Studies, vol. 90, pp. 14-26, 2016.

[54] K. Chu, D. Lee, G. Y. Kim, and J. Y. Kim, "Not All Communication is Created Equal : An Investigation into the Way to Improve Communication Quality on SNS," JOurnal of Korean Marketing Association, vol. 32, no. 2, pp. 103-124, 2017.

[55] C.-H. Chiang and J.-C. Wang, "The impact of interaction networks on lurkers' behavior in online community," in Proceedings of the 48th Annual Hawaii International Conference on System Sciences, HICSS 2015, pp. 1645-1656, USA, January 2015.

[56] Q. Li and J. Gu, "Activity driven modelling of online social network," Journal of Systems Engineering, vol. 30, pp. 9-15, 2015.
[57] R. Andersen and A. I. Mørch, "Mutual development in mass collaboration: Identifying interaction patterns in customerinitiated software product development," Computers in Human Behavior, vol. 65, pp. 77-91, 2016.

[58] P. Baumgartner and N. Peiper, "Utilizing Big Data and Twitter to Discover Emergent Online Communities of Cannabis Users," Substance Abuse: Research and Treatment, vol. 11, 2017.

[59] X. J. Liu, Z. Narisa, and X. L. Cui, "Construction and application of the complex network about consumer online reviews based on latent Dirichlet allocation model," Systems Engineering, vol. 32, no. 3, pp. 305-312, 2017.

[60] P. V. Marsden, "Interviewer effects in measuring network size using a single name generator," Social Networks, vol. 25, no. 1, pp. 1-16, 2003.

[61] H. R. Bernard, P. Killworth, D. Kronenfeld, and L. Sailer, "The problem of informant accuracy: the validity of retrospective data.," Annual Review of Anthropology, pp. 495-517, 1984.

[62] C. T. Butts, "Network inference, error, and informant (in)accuracy: A Bayesian approach," Social Networks, vol. 25, no. 2, pp. 103-140, 2003.

[63] Huawei Pollen Club, Application Center: Application of Technical Talent, 2017, https://cn.club.vmall.com/thread-117497951-1.html.

[64] Huawei Pollen Club, Application Center: Application of Management Talent, 2017, https://cn.club.vmall.com/thread-117496291-1.html.

[65] Huawei Pollen Club, Application Center: Application of Pollen Talent, 2017, https://cn.club.vmall.com/thread-117482311-1.html.

[66] Huawei Pollen Club, Application Center: Application of Pollen Girl, 2017, https://cn.club.vmall.com/thread-11747691-1-1.html.

[67] Huawei Pollen Club, Application Center: Rules of Area Management, 2017, https://cn.club.vmall.com/thread-11747831-1-1.html.

[68] Huawei Pollen Club, Application Center: Application Form and Format of Pollen Club, 2017, https://cn.club.vmall.com/thread13295938-1-1.html.

[69] G. R. Chen, X. F. Wang, and X. Li, Introduction to complex network: Models, structures and dynamics, Higher Education Press, Beijing, China, 2012.

[70] V. D. Blondel, J. Guillaume, R. Lambiotte, and E. Lefebvre, "Fast unfolding of communities in large networks," Journal of Statistical Mechanics: Theory and Experiment, vol. 2008, no. 10, Article ID P10008, pp. 155-168, 2008.

[71] C. J. Liu, Community ditection and analytical application in complex networks [Dissertation, thesis], Shandong University, 2014.

[72] J. Fu, J. Wu, C. Liu, and J. Xu, "Leaders in communities of real-world networks," Physica A: Statistical Mechanics and its Applications, vol. 444, pp. 428-441, 2016.

[73] J. Iranzo, J. M. Buldú, and J. Aguirre, "Competition among networks highlights the power of the weak," Nature Communications, vol. 7, p. 13273, 2016.

[74] S. Boccaletti, G. Bianconi, and R. Criado, "The structure and dynamics of multilayer networks," Physics Reports, vol. 544, no. 1, pp. 1-122, 2014. 


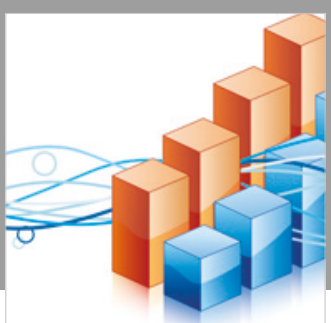

Advances in

Operations Research

\section{-n-m}
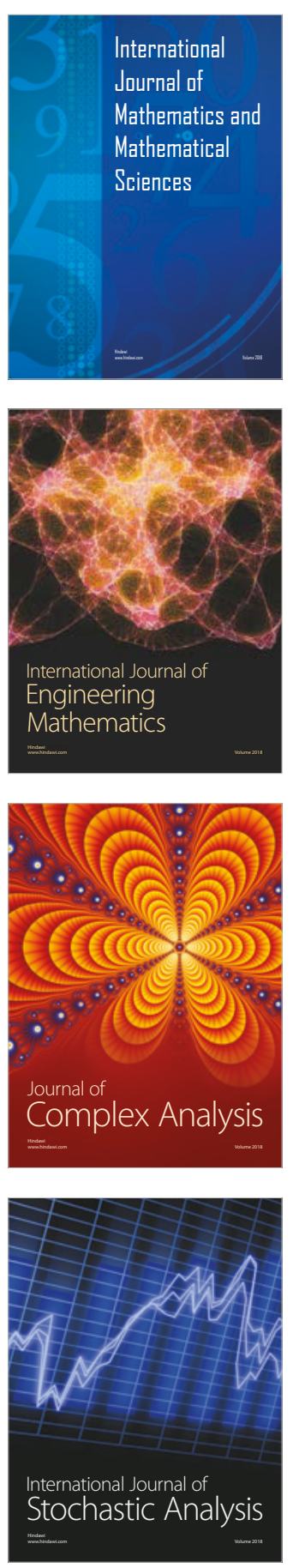
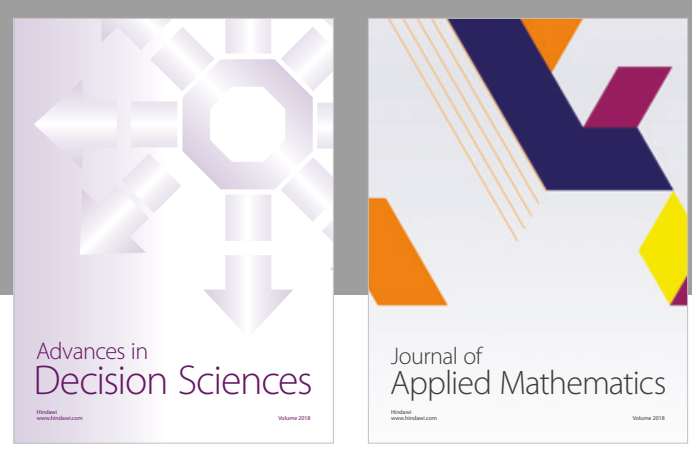

Journal of

Applied Mathematics
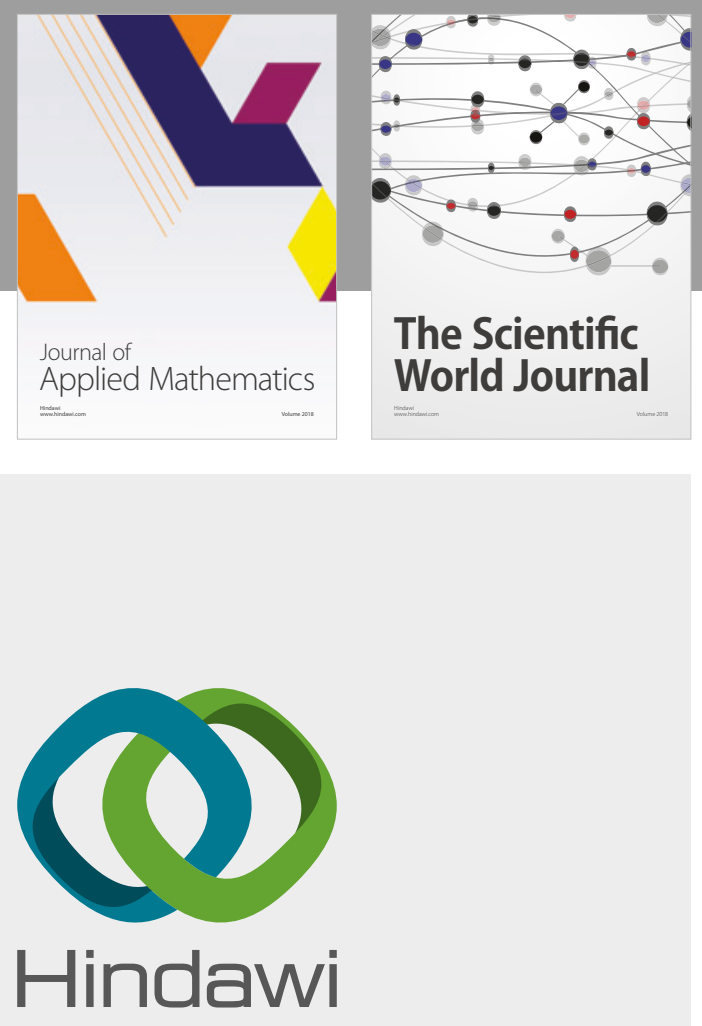

Submit your manuscripts at

www.hindawi.com

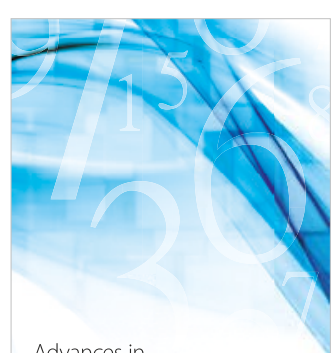

Advances in
Numerical Analysis
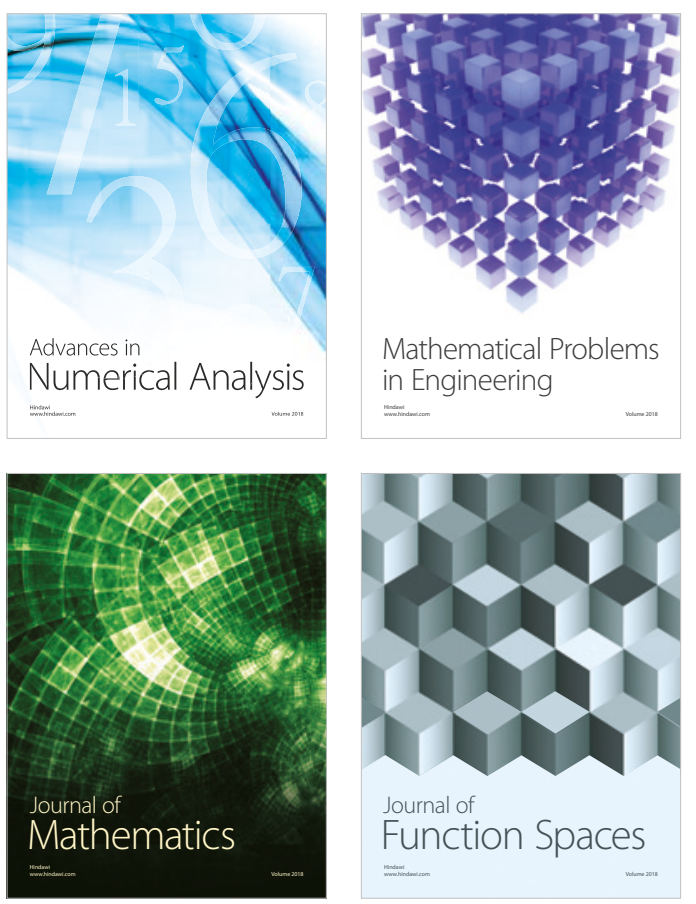

Mathematical Problems in Engineering

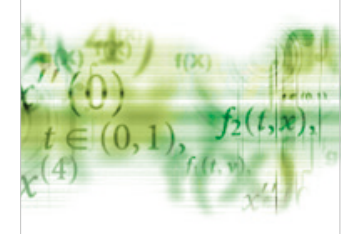

International Journal of

Differential Equations

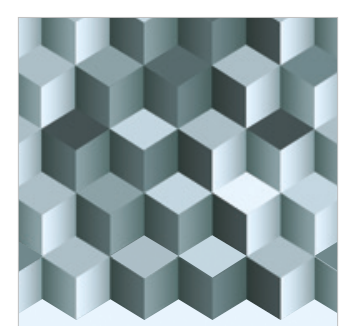

Journal of

Function Spaces
The Scientific

World Journal

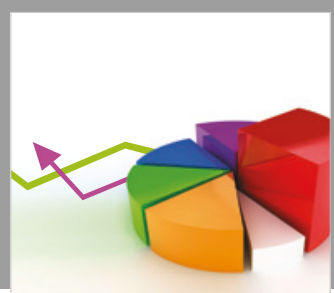

Journal of

Probability and Statistics
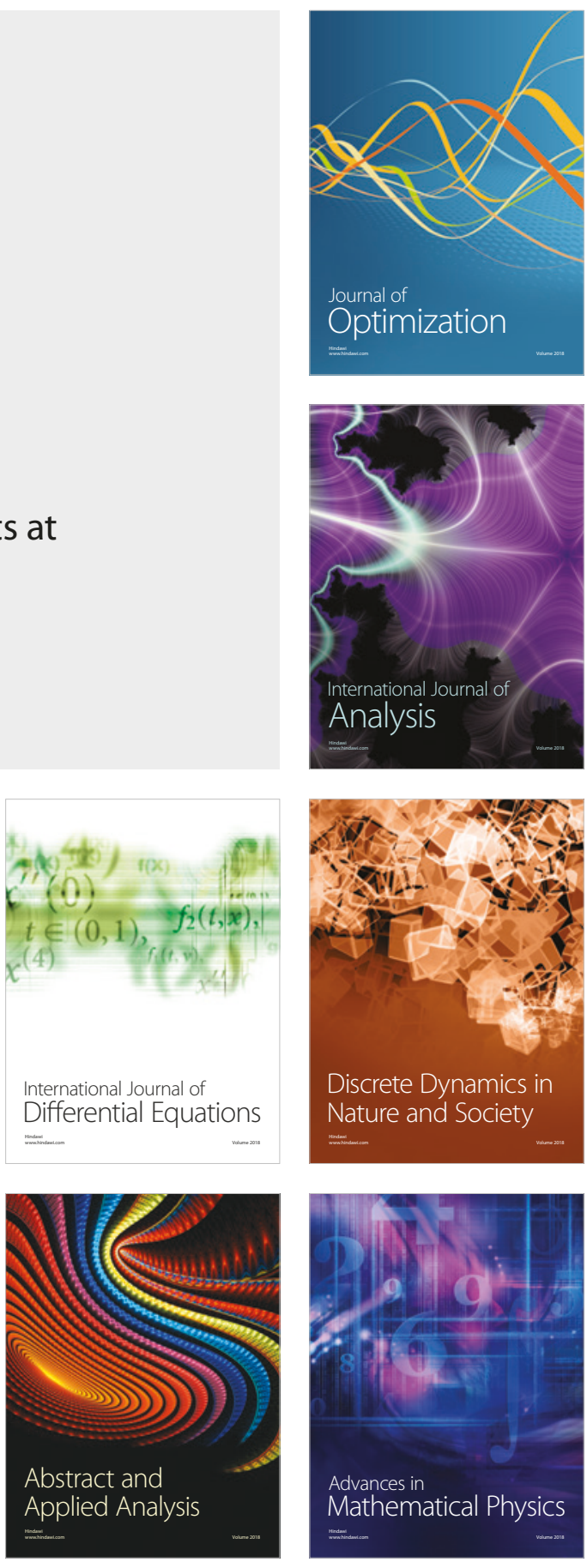